\title{
Un aporte al entendimiento de la lignificación de los pastizales/sabanas del Chaco Semiárido sudamericano
}

\author{
Rubén D. Coria ${ }^{1, \otimes}$; CARLos R. Kunst ${ }^{2} \&$ SANDRA J. Bravo ${ }^{3}$ \\ ${ }^{1}$ INTA Estación Experimental Agropecuaria Santiago del Estero. ${ }^{2}$ Colegio de Ingenieros Agrónomos de Santiago del Estero. \\ ${ }^{3}$ Facultad de Ciencias Forestales, Universidad Nacional de Santiago del Estero.
}

\begin{abstract}
Resumen. Aunque los pastizales/sabanas del Chaco Semiárido sudamericano se han lignificado masivamente, la ecología del fenómeno es poco conocida y las iniciativas de restauración son casi inexistentes. Aportamos información sobre: 1) las diferencias en la estructura y la diversidad vegetal a lo largo de un gradiente de lignificación, y 2) la asociación de atributos estructurales y funcionales con factores ambientales. En 38 unidades de muestreo obtuvimos la cobertura arbórea y arbustiva, biomasa herbácea, riqueza y composición de gramíneas y leñosas, y diversos tipos funcionales de herbáceas (principalmente de gramíneas). Los factores ambientales fueron intensidad histórica de pastoreo y frecuencia de fuego. En relación con el punto 1: a) la cobertura arbustiva fue significativa y progresivamente mayor a lo largo del gradiente de lignificación, y superó ampliamente a la cobertura arbórea, b) la biomasa herbácea fue significativamente menor con una cobertura leñosa alta ( $\bar{x}=89.7 \%), c)$ la riqueza de gramíneas fue máxima en niveles intermedios de cobertura leñosa ( $\mathrm{x}=39.3 \%$ y $64 \%$ ), d) la disimilitud en la composición de gramíneas, fue máxima entre los niveles muy bajo y alto de cobertura leñosa ( $\bar{x}=15.8 \%$ y $89.7 \%)$, y e) la riqueza y composición de leñosas fueron uniformes a lo largo del gradiente de lignificación. En cuanto al punto 2: 1) el incremento en la intensidad histórica de pastoreo se asoció significativa y fuertemente con la reducción en la frecuencia de fuego, lo cual, a su vez, se asoció significativamente con el incremento en la cobertura arbórea y arbustiva y con el decrecimiento en la biomasa herbácea (sugiriendo que el sobrepastoreo reduce o elimina la ocurrencia de fuegos de pastizal y promueve la lignificación), y 2) diversos tipos funcionales de gramíneas se asociaron significativamente con la intensidad histórica de pastoreo y la frecuencia de fuego. Nuestros resultados sirven para trazar estrategias para restaurar y manejar los pastizales/sabanas.
\end{abstract}

[Palabras clave: cobertura leñosa, cobertura arbustiva, biomasa herbácea, tipos funcionales de plantas, diversidad, restauración, intensidad de pastoreo, frecuencia de fuego]

\begin{abstract}
A contribution to the understanding of the woody encroachment in grasslands/savannas from the South American Semiarid Chaco. The grassland/savannas in the South American Semiarid Chaco have been massively transformed into shrubland. However, the ecology of this phenomenon is little known and restoration initiatives almost non-existent. We provide information about 1 ) the differences in plant structure and diversity along a woody encroachment gradient, and 2) the association among plant structural and functional attributes with environmental factors. We utilized 38 sample units and obtained tree and shrub cover, herbaceous biomass, species richness and composition of grasses and woody plants and several herbaceous functional types (mainly grasses). The environmental factors were historic grazing intensity and fire frequency. Related to item 1, we found: a) shrub cover was significant and progressively greater along the woody encroachment gradient and largely exceeded the tree cover, $\mathrm{b}$ ) the herbaceous biomass was significantly smaller, with a high woody cover $(\bar{x}=89.7 \%), c)$ the grass species richness was maximum at intermediate levels of woody cover $(\bar{x}=39.3 \%$ and $64 \%), d$ ) the dissimilarity in grass species composition was maximum between very low and high levels of woody cover ( $\bar{x}=15.8 \%$ and $89.7 \%$ ), and e) woody species richness and composition were uniform along the woody encroachment gradient. In relation to item 2, we observed: 1) the increase in historic grazing intensity was significant and strongly associated with the reduction of fire frequency, which, in turn, was significantly associated with the increase in tree and shrub cover and the decrease in herbaceous biomass, suggesting that overgrazing reduces or eliminates the grassland fires and promotes the woody encroachment, and 2) several grass functional types were significantly associated with the historic grazing intensity and fire frequency. Our results are useful both to anticipate the grassland/savannas responses to woody encroachment processes and to plan restoration and management strategies.
\end{abstract}

[Keywords: woody cover, shrub cover, herbaceous biomass, plant functional types, plant diversity, restoration, grazing intensity, fire frequency]

Editor asociado: Ricardo Grau

rudacoria@yahoo.com.ar
Recibido: 15 de Enero de 2021

Aceptado: 24 de Mayo de 2021 


\section{INTRODUCCIÓN}

En los últimos 150 años, muchos pastizales/ sabanas áridos y semiáridos del mundo sufrieron un proceso de lignificación a partir del establecimiento y propagación de plantas leñosas ( $D^{\prime}$ Odorico et al. 2012). Este proceso, llamado woody encroachment o shrub encroachment en la literatura inglesa, se define como el incremento en la densidad, la cobertura y la biomasa de plantas leñosas (Van Auken 2009). La cobertura arbustiva suele aumentar de forma sustancial, mientras que la arbórea exhibe respuestas variables (Eldridge et al. 2011). El fenómeno impacta negativamente sobre la producción pastoril y altera la biodiversidad, los ciclos hidrológicos y el balance de carbono de los ecosistemas (Archer et al. 2017). A escalas espaciales amplias y largos períodos de tiempo, el balance entre leñosas y herbáceas es afectado por el calentamiento global y el incremento de las concentraciones de $\mathrm{CO}_{2}$ en la atmósfera (Archer et al. 2017). A escala local, dicho balance varía según la geomorfología, la topografía, los tipos de suelos y los disturbios naturales y antrópicos (Archer et al. 2017).

A lo largo de la historia, el fuego pudo haber contribuido a controlar las plantas leñosas y mantener la dominancia de las plantas herbáceas en los pastizales/sabanas (Morello and Adamoli 1974; Allen 2008; D'Odorico et al. 2012). La intensidad de pastoreo interactúa con los regímenes de fuegos a través de regular la producción de biomasa herbácea (i.e., combustible fino), que propaga los fuegos de pastizal (Allen 2008; Scott et al. 2013). El sobrepastoreo crónico disminuye drásticamente la producción de biomasa herbácea, lo que, a su vez, reduce la ocurrencia de fuegos y promueve la proliferación de plantas leñosas y la erosión del suelo (Morello and Adamoli 1974; Van Auken 2009; D'Odorico et al. 2012). El mecanismo descripto fue denominado como la 'hipótesis del sobrepastoreo', y a escala local sería la causa dominante de la lignificación en diversas regiones áridas y semiáridas (Van Auken 2009).

La lignificación ejerce una influencia fuerte en la diversidad y los tipos funcionales de plantas (Bestelmeyer et al. 2003; Archer et al. 2017). A medida que la lignificación progresa, las especies adaptadas a pastizales/sabanas decrecen con el tiempo y son reemplazadas por otras adaptadas a arbustales/bosques (Archer et al.2017), por lo cual, la máxima diferencia en las composiciones de especies ocurriría entre niveles bajos y altos de lignificación. Con frecuencia, la máxima riqueza de especies ocurre cuando tanto el componente herbáceo como el leñoso están bien representados, es decir a niveles intermedios de lignificación (Archer et al. 2017). El sobrepastoreo puede inducir a la dominancia de las leñosas no palatables y el reemplazo de las gramíneas palatables perennes por hierbas o gramíneas anuales (Vetter 2005; Evans et al. 2017). Los fuegos recurrentes típicos de áreas dominadas por herbáceas generan hábitats con alta disponibilidad de luz solar que benefician a las especies intolerantes a la sombra y excluyen a las intolerantes al fuego (Ripley et al. 2015).

El Chaco Semiárido es una vasta planicie sedimentaria que en Sudamérica ocupa partes de la Argentina, Bolivia y Paraguay (Iriondo 1993). Hasta principios del siglo XX, las referencias históricas indican que el paisaje nativo estuvo dominado por un mosaico de bosques, pastizales y sabanas (Bucher 1982; Morello et al. 2013). En general, a escala local (i.e., $500 \mathrm{~m}$ - pocos kilómetros), estos tipos de vegetación estuvieron distribuidos a lo largo de un ligero gradiente topográfico: 1) bosques en posiciones elevadas, 2) pastizales/sabanas en posiciones bajas, y 3) bosques abiertos (i.e., ecotonos entre los anteriores) en las posiciones intermedias (Morello and Saravia Toledo 1959; Morello and Adamoli 1968; Iriondo 1993; Kunst et al. 2006) (Figura 1a). Este vínculo entre posición topográfica y tipos de vegetación ha sido considerado como tres sitios ecológicos diferentes, definidos por Kunst et al. (2006) como altos, medias lomas y bajos. Desde principios del siglo XX, la fisonomía de este paisaje original comenzó a ser muy modificada por un incremento progresivo de la cobertura leñosa de baja altura ocurrido tanto en bosques como en pastizales/sabanas, que derivó en una homogeneización masiva del paisaje (Figura 1b) (Adamoli et al. 1972; Kunst et al. 2006). Las principales causas citadas son, en bosques, la tala de árboles y el sobrepastoreo, y en pastizales/sabanas, el sobrepastoreo y la supresión de fuegos; en ambos casos, intensificado por sequías (Adamoli et al. 1972; Kunst et al. 2006).

La lignificación masiva de pastizales/ sabanas de la región impactó de manera severa en aspectos ecológicos y productivos. Leñosas colonizadoras comunes son Geoffroea decorticans, Aspidosperma quebracbo-blanco, Vachellia aroma y otras especies pertenecientes a los géneros Prosopis y Acacia (Morello and 
Saravia Toledo 1959; Morello and Adamoli 1974). Numerosas gramíneas forrajeras intolerantes a la sombra típicas de pastizales/ sabanas (e.g., géneros Paspalum, Pappophorum, Cenchrus, etc.) prácticamente desaparecieron en los arbustales (Morello and Saravia Toledo 1959; Morello and Adamoli 1974; Kunst et al. 2006). Diversas especies de aves y mamíferos adaptados a pastizales/sabanas declinaron sus poblaciones por la lignificación de sus hábitats, los cambios en el uso de suelo y la caza ilegal (Chebez 2008; Grau et al. 2014; Torres et al. 2014). En situaciones de degradación extrema, la reducción de la receptividad ganadera supera el 90\% (Kunst et al. 2006). En la región, las iniciativas de restauración ecológica de los pastizales/sabanas son casi inexistentes. En contraposición, el paradigma de manejo dominante se focaliza en resolver la problemática pastoril a partir de reducir o eliminar la cobertura leñosa utilizando disturbios mecánicos (e.g., rolados) e implantar gramíneas forrajeras de origen africano. Se conoce poco acerca de los efectos de estas prácticas sobre la vegetación nativa.

En el Chaco Semiárido, el conocimiento sobre la ecología de la lignificación de los pastizales/sabanas es mayormente cualitativo y descriptivo. En consecuencia, se necesitan nuevos estudios para comprender mejor el fenómeno y avanzar en la restauración y uso sustentable de estos ecosistemas mediante aproximaciones cuantitativas. Nosotros indagamos en dos preguntas. 1) ¿Qué diferencias se observan en la estructura de la vegetación y en la diversidad de gramíneas y leñosas a lo largo de un gradiente de lignificación? 2) ¿Cómo se asocian los atributos estructurales y funcionales de la vegetación con factores ambientales como la intensidad histórica de pastoreo y la frecuencia de fuego? Nuestra hipótesis general fue que la lignificación es promovida por el sobrepastoreo y la consecuente reducción/ supresión de la ocurrencia de fuegos (i.e., hipótesis del sobrepastoreo). En relación con la primera pregunta, predecimos que 1) los principales cambios estructurales están dados por incrementos en la cobertura arbustiva (i.e., no en la cobertura arbórea) y por una reducción en la biomasa herbácea, 2) la máxima riqueza de gramíneas y leñosas ocurre en niveles intermedios del gradiente de lignificación, y 3) las mayores disimilitudes en la composición de gramíneas y leñosas se registran entre los extremos inferior y superior del gradiente de lignificación. Relacionado con la segunda pregunta, predecimos que 4) los atributos estructurales y funcionales de la vegetación se asocian de manera consistente con la intensidad histórica de pastoreo y la frecuencia de fuego. Aportamos también información para orientar la restauración ecológica y manejo sustentable de los pastizales/sabanas.

\section{Materiales y métodos}

\section{Área de estudio}

El área de estudio, se ubica en el sudoeste de la provincia de Santiago del Estero, Chaco Semiárido, Argentina (norte $=28^{\circ} 04^{\prime} 15.60^{\prime \prime} \mathrm{S}$, sur $=28^{\circ} 30^{\prime} 50.02^{\prime \prime} \mathrm{S}$, oeste $=65^{\circ} 05^{\prime} 42.53^{\prime} \mathrm{O}$ y este $=64^{\circ} 33^{\prime} 27.09^{\prime \prime}$ O) (Figura 2). El clima es semiárido subtropical, con inviernos fríos y secos, y veranos cálidos y lluviosos (Boletta 1998). El promedio anual de precipitaciones oscila entre 500-600 mm (Noe et al. 2012) y los balances hídricos son bastante homogéneos (e.g., si ocurren sequías o excesos hídricos, mayormente afectan a todo el lugar por igual) (Ravelo et al. 2014). A escala cartográfica 1: 500000, el área de estudio es una planicie suave (i.e., pendientes generales entre 0.5 y $2 \%$ ) cubierta por sedimentos loessicos, subdividida a su vez en tres unidades geomorfológicas (i.e., Planicie Ondulada Norte, Planicie Sur y Estribaciones Serranas) (Angueira and Vargas Gil 1993; Kunst et al. 2006) (Figura 2). Los suelos pertenecen a los Grandes Grupos de los Haplustoles y Natrusoles, siendo los primeros los dominantes (Angueira et al. 2007).

En cada unidad geomorfológica mencionada, a escala cartográfica 1:20000, el gradiente de sitios ecológicos (i.e., altos, medias lomas y bajos) (Figura 1) se desarrolla principalmente entre 1-2 $\mathrm{km}$ de distancia (Kunst et al. 2006). A escala local, estos sitios ecológicos correlacionan bien con las variaciones espaciales de las comunidades de plantas y son las unidades de ecosistemas empleadas con propósitos de investigación y manejo (Kunst et al. 2006). Los sitios ecológicos altos estuvieron ocupados originalmente por bosques altos de madera dura, con un estrato arbóreo superior integrado por A. quebracho-blanco y Schinopsis lorentzii, aunque la mayoría de estos bosques fueron convertidos en bosques y arbustales secundarios. Los sitios ecológicos medias lomas originalmente estuvieron ocupados por ecotonos entre bosques altos y pastizales/ sabanas. En el presente, estos ecotonos están en su mayoría lignificados, con abundancia 
a) Paisaje bien conservado Bosques abiertos (i.e. ecotonos)
en posiciones intermedias

Pastizales y sabanas en posiciones bajas

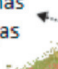

Bosques altos en posiciones altas

\author{
)
}

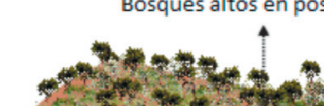

a $3=3$

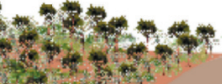

$+\ldots$

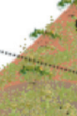

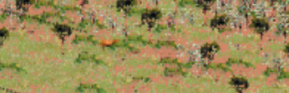

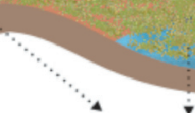

Las depresiones en posiciones bajas

pueden almacenar agua temporariamente

b) Paisaje degradado

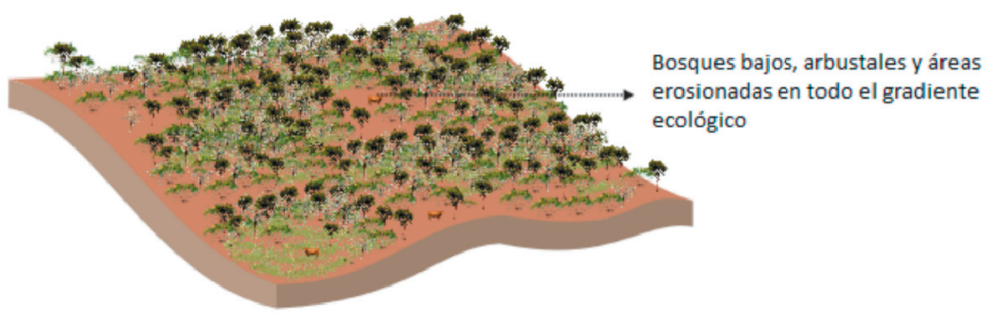

Figura 1. Modelo general del paisaje a escala local en el Chaco Semiárido.

Figure 1. General model of the landscape at local scale in the Semiarid Chaco.
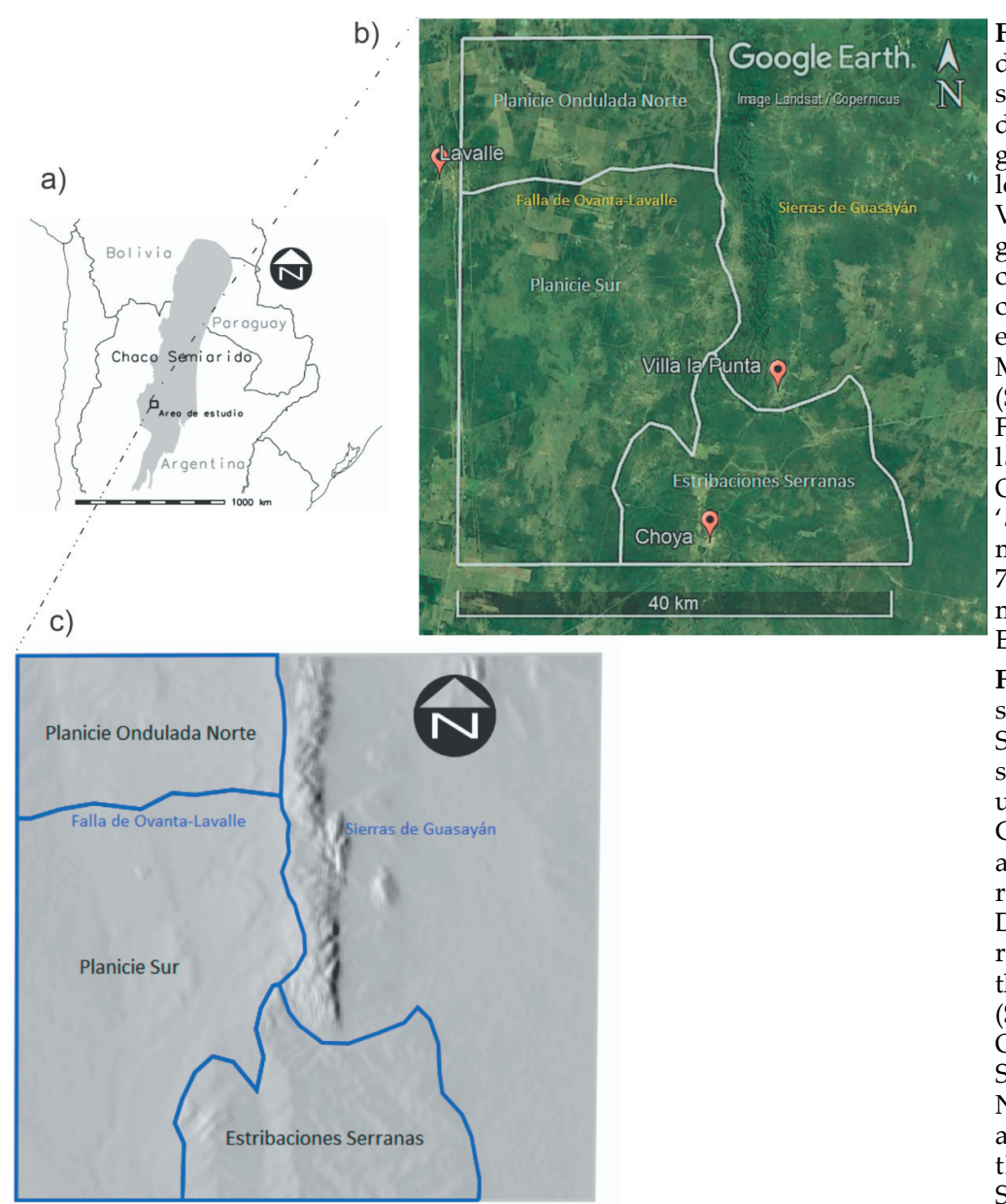

Figura 2. a) Localización del área de estudio en el Chaco Semiárido sudamericano. b) Vista del área de estudio, con las unidades geomorfológicas delimitadas y los pueblos de Lavalle, Choya y Villa la Punta como referencias geográficas. La imagen remota corresponde a diciembre de 1994. c) Vista del relieve del área de estudio, elaborado a partir de un Modelo Digital de Elevaciones (SRTM; resolución: 30x30 m). La Falla de Ovanta-Lavalle separa la Planicie Sur de la Planicie Ondulada Norte. Las subfiguras ' $a$ ' y ' c' fueron elaboradas mediante el software GRASS GIS 7.8. La subfigura ' $b$ ' fue elaborada mediante la aplicación Google Earth Pro 7.3.3.7786 (64-bit).

Figure 2. a) Localization of the study area in the South American Semiarid Chaco. b) View of the study area, with geomorphologic units delimited and Lavalle, Choya and Villa la Punta towns as geographic references. The remote image corresponds to December 1994. c) View of the relief of the study area, elaborated through a Digital Elevation Model (SRTM; resolution: 30x30 m). The Ovanta-Lavalle fault separates the Southern Plain from the Rolling Northern Plain. Subfigures ' $a$ ' and ' $c$ ' were elaborated using the software GRASS GIS 7.8. Subfigure ' $b$ ' was elaborated using the Google Earth Pro 7.3.3.7786 (64-bit) application. 
de árboles de A. quebracho-blanco y P. nigra y arbustos como $V$. aroma y Celtis ehrenbergiana. Los sitios ecológicos bajos, donde este estudio hizo foco, estuvieron ocupados en sus orígenes por pastizales/sabanas, con árboles dispersos de $S$. lorentzii y A. quebracho-blanco, arbustos como $V$. aroma, G. decorticans y Aloysia sp. y gramíneas heliófilas como Elionurus muticus, Schizachyrium tenerum, Paspalum sp., Pappophorum sp. y Bothriochloa sp., entre otras. Cuando estos pastizales/sabanas están arbustificados, abundan $V$. aroma, P. nigra, Geoffroea decorticans y Schinus sp. Además de recibir el agua directa de las precipitaciones, las posiciones topográficas locales bajas son sumideros de la escorrentía desde las posiciones más elevadas, y debido a sus pendientes suaves (i.e., <3\%) pueden anegarse de manera temporaria (Angueira 2007). Ello configura ambientes más húmedosy favorables para la productividad de las pasturas nativas (Morello and Adamoli 1974).

\section{Unidades de muestreo}

Las unidades de muestreo empleadas en este estudio formaron parte de una base de datos más amplia generada por el INTA EEA Santiago del Estero en la década de 1990.

Características de la base de datos completa. Se obtuvo dividiendo el área de estudio en ecosistemas homogéneos por medio del método de desagregación progresivo y jerárquico (Gastó et al. 1990, 1993), muy similar al modelo de balance entre leñosas y herbáceas de Archer et al. (2017). En este método, el primer factor determinante del ecosistema es el clima, que actúa en el tope de la jerarquía. Luego, la geomorfología, la topografía local, el tipo de suelo y los disturbios naturales y antrópicos actúan en orden jerárquico a escala local. La base de datos completa cuenta con 110 unidades de muestreo distribuidas en las tres unidades geomorfológicas antes mencionadas (38 en la Planicie Sur, 46 en la Planicie Ondulada Norte y 26 en las Estribaciones Serranas). A su vez, por cada unidad geomorfológica, las unidades de muestreo se distribuyeron en los tres sitios ecológicos. El sistema de muestreo se especifica a continuación. 1) Cada unidad de muestreo fue una parcela (superficie $=1 \mathrm{ha}$ ) ubicada en un potrero diferido y alambrado. La técnica del diferimiento consiste en suprimir el pastoreo durante la estación de crecimiento para brindar un descanso al pastizal o crear reservas de forraje henificado en pie para el invierno y principio de la primavera (Díaz 2015). De esta manera, las parcelas seleccionadas no tuvieron pastoreo durante la estación de crecimiento previa a las mediciones de campo. 2) En cada unidad geomorfológica se seleccionaron diferentes localizaciones en campos dedicados a cría bovina mediante interpretación de imágenes remotas. Dentro de cada localización se muestrearon al menos dos unidades de muestreo independientes. 3) En el contexto del paisaje local, las posiciones topográficas relativas (i.e., altas, intermedias y bajas) fueron determinadas de forma visual evaluando la orientación de las pendientes, la dirección del movimiento superficial del agua de lluvia y la acumulación de mantillo. La base de datos completa fue utilizada previamente en dos estudios; el primero, referido a la delimitación de ecosistemas homogéneos (Kunst et al. 2006), y el segundo, sobre gramíneas indicadoras de la condición del pastizal con fines pastoriles (Kunst et al. 2007).

Unidades de muestreo utilizadas en este estudio. De la base de datos completa antes presentada, reutilizamos sólo las unidades de muestreo ubicadas en los sitios ecológicos bajos. Estas unidades de muestreo fueron 38 en total (16 en la Planicie Ondulada Norte, 19 en la Planicie Sur y 3 en las Estribaciones Serranas) y se relevaron entre 1992 y 1994. Desafortunadamente, la cartografía original en soporte papel se extravió y tampoco hay un registró de coordenadas geográficas (i.e., durante los años en que se realizó el trabajo de campo, aún no se había liberado el sistema GPS para uso civil en el planeta). Por lo tanto, no es posible mostrar las ubicaciones precisas de estas unidades de muestreo.

El Índice Normalizado de Precipitación (SPI) de tres meses refleja de manera confiable las condiciones de humedad a corto y mediano plazo, y proporciona una estimación estacional de la precipitación (Svoboda et al. 2012; Ravelo et al. 2014). En el área de estudio, el índice SPI de tres meses, durante el tiempo de estudio (i.e., desde el inicio de la temporada de crecimiento 1991-1992 hasta el final de la temporada de crecimiento 19931994, es decir octubre de 1991 a marzo de 1994) indican eventos de sequía incipiente en algunos períodos de 1993 (SPI de tres meses de abril, junio, julio, agosto, septiembre y diciembre) y 1994 (SPI de tres meses de enero y marzo), siendo las precipitaciones en el resto de los períodos normales o por encima de lo 
normal (Ravelo et al. 2014) (ver metodología de estimación en Material Suplementario A). Por lo tanto, durante este estudio no hubo restricciones hídricas fuertes para la productividad herbácea.

\section{Muestreo y atributos de la vegetación}

Estrato herbáceo. La biomasa herbácea total y por especie ( $\mathrm{kg} \mathrm{MS} / \mathrm{ha})$ se estimó mediante el método BOTANAL (Tothill et al. 1978). El método se aplicó al final de la estación de crecimiento (i.e., otoño) para captar la máxima expresión de la productividad y la diversidad del estrato herbáceo. La nomenclatura de las especies fue actualizada según el Instituto de Botánica Darwinion (2017). El método consta de dos partes. 1) Estimación de la biomasa herbácea. Por cada unidad de muestreo se estimó de manera visual mediante 52 submuestras aleatorias (i.e., $\operatorname{marco}=0.25 \mathrm{~m}^{2}$ ). Cada submuestra recibió una calificación de 1 a 5 , en la que 1 representa la menor cantidad de biomasa herbácea y 5 la máxima cantidad. Las calificaciones 2 a 4 representan una gradación entre las anteriores. Se utilizaron como referencia cinco marcos patrones previamente seleccionados y debidamente identificados, los cuales representaron la escala de 1 a 5 que contuvo a las variaciones de la biomasa herbácea antes descriptas. Una vez hechas las lecturas visuales, los marcos patrones (i.e., dos por cada calificación del 1 al 5) se cortaron y se secaron en estufa (i.e., $60^{\circ} \mathrm{C}$ por $48 \mathrm{~h}$ ) para obtener los pesos secos. Con los valores de biomasa en los 5 marcos patrones se construyó una regresión lineal $(y=a+b x)$ que sirvió para estimar la disponibilidad de biomasa herbácea (y) partiendo del promedio de las lecturas visuales (x). 2) Estimación de la biomasa herbácea por especie. El método se basó en estimar visualmente qué especies ocupan el primero, segundo y tercer lugar, en términos de peso seco, en las mismas submuestras del paso anterior. La biomasa seca de la especie $\mathrm{i}\left(\mathrm{y}_{\mathrm{i}}\right)$, se estimó como

$$
\underset{/ 100}{\mathrm{y}_{\mathrm{i}}=\left(\mathrm{p} 1_{\mathrm{i}} * 70.19+\mathrm{p} 2_{\mathrm{i}} * 21.08+\mathrm{p} 3_{\mathrm{i}} * 8.73\right) * \mathrm{y}}
$$

donde $\mathrm{p} 1_{i}, \mathrm{p} 2_{\mathrm{i}} \mathrm{y} \mathrm{p} 3_{\mathrm{i}}$ representan la proporción de submuestras en que la especie i se registró en el primer, segundo y tercer lugar, respectivamente, e y representa la biomasa herbácea total obtenida en el paso anterior.

Los tipos funcionales de plantas, se definen como grupos de plantas, frecuentemente polifiléticos, que presentan respuestas similares a factores ambientales y producen efectos similares en los principales procesos ecosistémicos (Walker 1992). A partir de la biomasa herbácea por especie formamos diferentes tipos funcionales. Utilizamos el método a priori, basado en general en un solo carácter funcional que se fija antes de la tipificación (Díaz et al. 2002) (Material Suplementario B). a) Herbáceas según su forma de vida, con dos clases: gramíneas y hierbas (Instituto de Botánica Darwinion 2017). b) Gramíneas según su ciclo de vida, con dos clases: perennes y anuales (Instituto de Botánica Darwinion 2017). c) Gramíneas según su tolerancia a la sombra, con dos clases: tolerantes e intolerantes (Morello and Saravia Toledo 1959; Kunst et al. 1998, 2006, 2007; Molina and Rúgolo de Agrasar 2006). d) Gramíneas según su tolerancia al fuego, con dos clases de tolerancia: alta y mediabaja (Kunst et al. 1998). En este caso, no hubo información suficiente para clasificar a las todas gramíneas según sus tolerancias al fuego, por lo cual la clase de tolerancia alta agrupó sólo a seis especies y la clase de tolerancia media-baja agrupó sólo a cinco especies. e) Gramíneas según su palatabilidad, con dos clases: palatables (i.e., especies de valor forrajero) y poco palatables (i.e., especies poco o nada consumidas) (Morello and Saravia Toledo 1959; Kunst et al. 1986, 1998; Díaz 2015; Ledesma et al. 2017).

Estrato leñoso. Fue utilizado el método Point transect modificado (Passera et al. 1983). En cada unidad de muestreo, a lo largo de una transecta, se evaluaron 52 puntos de muestreo con $50 \mathrm{~cm}$ de separación entre ellos. En cada punto de muestreo se colocó una vara telescópica en posición vertical y se contó los contactos entre la vara y los órganos de las plantas leñosas, distinguiendo entre especies y tipos de cobertura contactados (i.e., arbórea $>3 \mathrm{~m}$ y arbustiva $\leq 3 \mathrm{~m}$ ). A partir de estas mediciones, obtuvimos las siguientes variables: 1$)$ cobertura leñosa total, arbórea y arbustiva (\%), a partir del porcentaje de puntos de muestreo donde hubo contacto con cada tipo de cobertura, y 2) cobertura leñosa por especie (contactos/transecta), contabilizando los respectivos contactos.

\section{Factores ambientales}

Los siguientes factores ambientales fueron además estimados.

Frecuencia de fuego. Definido por el conteo de veces que cada unidad de muestreo se quemó 
totalmente en los 10 años previos al muestreo, tomando como referencia inicial (i.e., tiempo 0) el año en que se realizó el muestreo (i.e., recuérdese que los muestreos se realizaron entre 1992/94). La variable se estimó a través de entrevistas a los productores ganaderos, complementada con indicadores de campo como cicatrices de fuego en troncos y ramas de árboles y presencia de especies pirófilas. Cada unidad de muestreo, fue clasificada en las siguientes categorías de frecuencia de fuego. Categoría 3, Alta (un fuego por año). Categoría 2, Media (un fuego cada 3 -4 años). Categoría 1, Bajo (al menos un fuego en los últimos 10 años). Categoría 0, Nulo (más de 10 años sin fuegos).

Intensidad histórica de pastoreo. La medida directa de intensidad de pastoreo más utilizada en estudios de largo plazo ha sido el porcentaje de forraje herbáceo consumido o destruido por los herbívoros (Holechek et al. 1999). Sin embargo, existen diversas medidas indirectas que pueden utilizarse, como el número y biomasa de estiércol (i.e., estimaciones a corto plazo), el ancho y profundidad de senderos de herbívoros (i.e., estimaciones a largo plazo) (Eldridge et al. 2017), la distancia a la aguada (i.e., estimaciones a corto y largo plazo) (Díaz 2015) y la condición del pastizal con fines pastoriles (i.e., estimaciones a largo plazo) (van Oudenhoven et al. 2015). En nuestro estudio, por cada unidad de muestreo, estimamos indirectamente la intensidad histórica de pastoreo (i.e., más de 20 años de uso) (Eldridge et al. 2017), a partir del porcentaje de área erosionada del suelo. Nuestra estrategia de estimación se fundamenta en que en las regiones áridas y semiáridas del mundo, el mantenimiento de la cobertura vegetal es clave para reducir la erosión, y la defoliación excesiva del estrato herbáceo a causa del pastoreo intenso acelera la erosión y la pérdida de materia orgánica y de nutrientes de suelo (Abril and Bucher 1999; Van Auken 2000; Bestelmeyer et al. 2003; Zhao et al. 2007; Siffredi et al. 2011; D'Odorico et al. 2012; Díaz 2015; van Oudenhoven et al. 2015; Archer et al. 2017; Eldridge et al. 2017; Zhou et al. 2017).

La base de datos empleada, presenta una clasificación de las unidades de muestreo que tiene en cuenta las siguientes categorías de erosión del suelo. Categoría 3, Severa (más del $50 \%$ del área afectada por erosión). Categoría 2, Moderada (entre 50-30\% del área afectada por erosión). Categoría 1, Baja (menos del
$30 \%$ del área afectada por erosión). Categoría 0 , Nula (abundante mantillo o sin signos de pérdidas de suelo).

La erosión del suelo, fue evaluada a campo observando la acumulación de mantillo, presencia de pedestales y cárcavas y pérdidas superficiales de suelo. Los porcentajes de área erosionada se estimaron visualmente en marcos metálicos de $0.25 \mathrm{~m}^{2}$, con 52 submuestras por unidad de muestreo.

En nuestro estudio, las clases de erosión nula y severa se usaron como estimadores, respectivamente, de intensidades históricas de pastoreo bajas/nulas y muy intensas (i.e., extremos del disturbio). En cambio, las clases de erosión baja y moderada estimaron respectivamenteunagradacióndeintensidades históricas de pastoreo intermedias entre las anteriores.

\section{Análisis de datos}

Clasificación de las unidades de muestreo. Para analizar las modificaciones en los atributos estructurales y en la diversidad de gramíneas y leñosas (i.e., predicciones 1, 2 y 3) agrupamos arbitrariamente las unidades de muestreo en cuatro niveles de lignificación (i.e., cobertura leñosa total porcentual): muy bajo (0-25\%), bajo (25.1-50\%), moderado (50.1$75 \%)$ y alto $(75.1-100 \%)$.

Atributos estructurales. Las diferencias significativas en la cobertura arbórea, cobertura arbustiva y biomasa herbácea, fueron evaluadas usando ANOVA de un factor (nivel de lignificación) y prueba LSD de Fisher, $\alpha=0.05$. Previo al análisis, para sostener los supuestos de normalidad y homogeneidad de varianzas de los residuos, las coberturas arbórea y arbustivas (\%) fueron transformadas por el método del arcoseno (i.e., adecuado cuandola variable es una proporción), mientras que la biomasa herbácea fue transformada por el método de la raíz cuadrada (Fowler and Cohen 1990). Los análisis se realizaron con el Software INFOSTAT versión 2013 (Di Rienzo et al. 2013).

Diversidad de especies. La biomasa de gramíneas por especie (kgMS/ha) y la cobertura leñosa por especie (contactos/transecta), fueron convertidos a presencia-ausencia por especie para realizar los siguientes análisis (Colwell 2013): a) obtener el estimador no paramétrico Chao2 de la riqueza de gramíneas y leñosas por cada nivel de lignificación, b) comparar 
estadísticamente la riqueza de gramíneas y leñosas entre niveles de lignificación por medio del método de rarefacción basado en muestras y extrapolación. El procedimiento, equipara los tamaños de muestras más pequeños a la muestra de mayor tamaño y produce una estimación de la riqueza acumulada de especies con los respectivos intervalos de confianza al 95\%. La no superposición de los intervalos de confianza, indican diferencias significativas en la riqueza de especies al nivel $\alpha=0.05$, y c) obtener el estimador no paramétrico Chao-Sorensen de la similitud en la composición de especies de gramíneas y leñosas entre los pares de niveles de lignificación. Los valores se multiplicaron por 100 para obtener el porcentaje de similitud. Las clases de similitudes fueron: 0-39.9\% (baja), 40-69,9\% (moderada) y 70-100\% (alta). Los análisis se realizaron con el Software EstimateS 9.10.0 (Colwell 2013).

Asociaciones entre atributos estructurales y funcionales con factores ambientales. Para evaluar estas asociaciones (i.e., predicción 4), utilizamos el coeficiente de correlación no paramétrico de Spearman, basado en rangos. Este coeficiente, se utiliza cuando una o las dos variables a correlacionar están en escala ordinal (i.e., en nuestro estudio, la frecuencia de fuego y la intensidad histórica de pastoreo) y el número de pares de muestras es igual o mayor a 7 (i.e., nuestro estudio tuvo 38 pares de muestras) (Fowler and Cohen 1990; Di Rienzo et al. 2013). La intensidad de las correlaciones (positivas o negativas), se categorizaron como sigue: 0-0.19 (muy débil), 0.2-0.39 (débil), 0.4-0.69 (moderada), 0.7-0.89 (fuerte) y 0.9-1 (muy fuerte) (Fowler and Cohen 1990). Las significancias de las correlaciones, fueron evaluadas al nivel $\alpha=0.05$. Los análisis se realizaron con el Software INFOSTAT versión 2013 (Di Rienzo et al. 2013).

\section{Resultados}

\section{Clasificación de las unidades de muestreo}

Por cada nivel de lignificación, los promedios (x) y desviaciones estándar (D.E.) de la cobertura leñosa total, así como los tamaños de muestras (n), fueron los siguientes: lignificación muy baja ( $\bar{x}=15.8 \%$, D.E. $=11.9 \%$, $\mathrm{n}=4)$, lignificación baja ( $\mathrm{x}=39.3 \%$, D. $\mathrm{E}=6.7 \%$, $\mathrm{n}=10)$, lignificación moderada $\left(\mathrm{x}^{-}=64.0 \%\right.$, D.E. $=9.3 \%, n=13)$ y lignificación alta $(\bar{x}=89.7 \%$, D.E. $=9.1 \%, n=11)$.

\section{Atributos estructurales}

La Figura 3 presenta los promedios y desviaciones estándar de los atributos estructurales de la vegetación, más los resultados de los análisis de la varianza. Consistente con la predicción 1, a) la cobertura arbustiva fue significativamente mayor a medida que progresó el gradiente de lignificación (Figura 3a), b) aunque en el nivel de lignificación más alto se observó una cobertura arbórea significativamente mayor respecto a los niveles de lignificación más bajos (Figura 3b), se advierte que a lo largo del gradiente de lignificación la cobertura arbustiva predominó ampliamente por sobre la cobertura arbórea (Figura 3a, 3b), y c) la biomasa herbácea fue significativamente menor en el nivel de lignificación alto respecto a los niveles de lignificación muy bajo y bajo (Figura 3c).

\section{Diversidad de especies}

El estimador Chao2 de la riqueza de especies, en promedio, estimó 17.6 especies de gramíneas en el nivel de lignificación muy bajo, 60.0 en el nivel bajo, 71.0 en el nivel moderado y 23.7 en el nivel alto. También, en promedio, estimó 19.2 especies leñosas en el nivel de lignificación muy bajo, 25.3 en el nivel bajo, 25.2 en el nivel moderado y 36.1 en el nivel alto. Las abundancias del listado completo de especies, se presentan en los materiales suplementarios B y C.

En el análisis de rarefacción y extrapolación (Figura 4), teniendo en mente que la falta de superposición de los intervalos de confianza indica diferencias significativas en la riqueza de especies, se aprecia que: a) consistente con la predicción 2, hubo un pico significativo en la riqueza de gramíneas en los niveles intermedios de lignificación (i.e., bajo y moderado) (Figura 4a), y b) no hubo diferencias significativas en la riqueza de leñosas entre niveles de lignificación (i.e., todos los intervalos de confianza se superpusieron) (Figura 4b), lo cual no es consistente con la predicción 2.

La Tabla 1 presenta los porcentajes de similitud de las composiciones de gramíneas y leñosas entre niveles de lignificación (i.e., índice Chao-Sorensen). Consistente con la predicción 3, para las gramíneas, la menor similitud se registró entre los niveles de lignificación muy bajo y alto (i.e., similitud moderada), mientras que entre el resto de los 

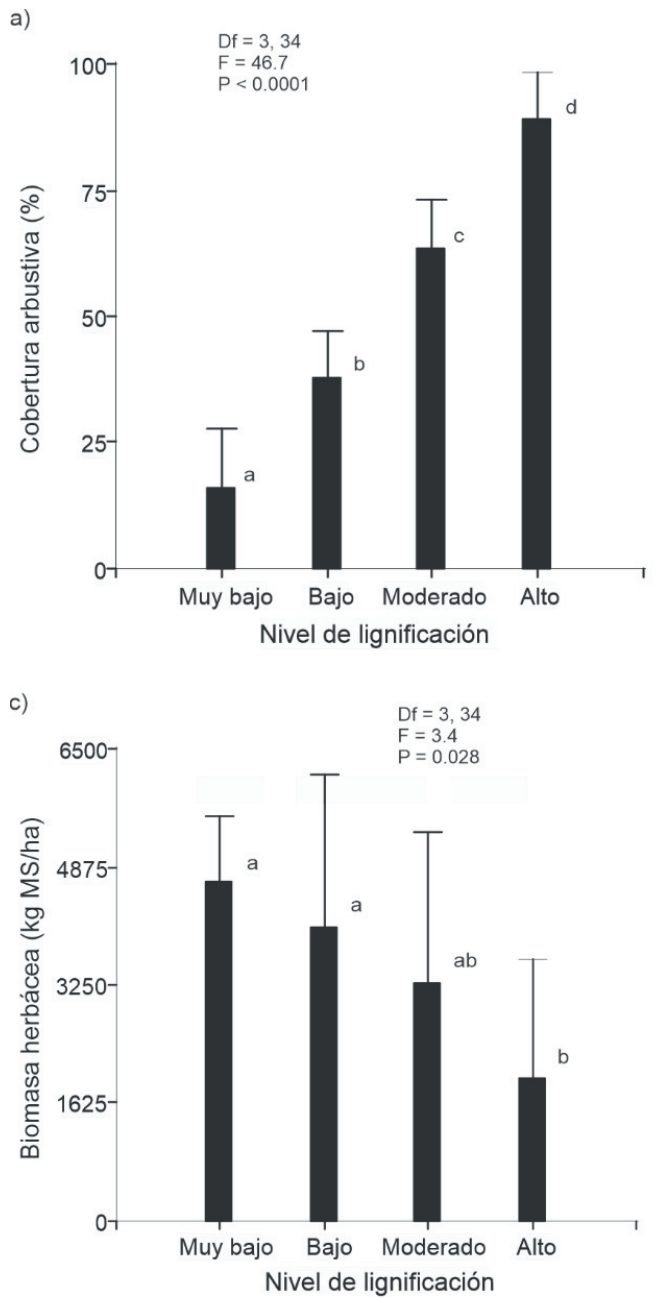

pares de niveles de lignificación, las similitudes fueron altas en todos los casos. Para las leñosas, aunque la menor similitud también se registró entre los niveles de lignificación muy bajo y alto, se destaca que todos los pares de niveles de lignificación mostraron altas similitudes, lo cual no concordó con la predicción 3.

\section{Asociaciones entre atributos estructurales y funcionales con factores ambientales}

La Tabla 2 presenta la matriz de correlaciones completa en formato tabular. A continuación, se destacan únicamente las correlaciones de interés para nuestro trabajo. Consistente con la predicción 4, los atributos estructurales $\mathrm{y}$ diversos atributos funcionales, se asociaron significativamente con los factores ambientales considerados. Muy importante, las correlaciones indicadas en los ítems 1 y 2, fueron coherentes con la hipótesis del sobrepastoreo y se detallan a continuación. 1) Frecuencia de fuego e intensidad histórica

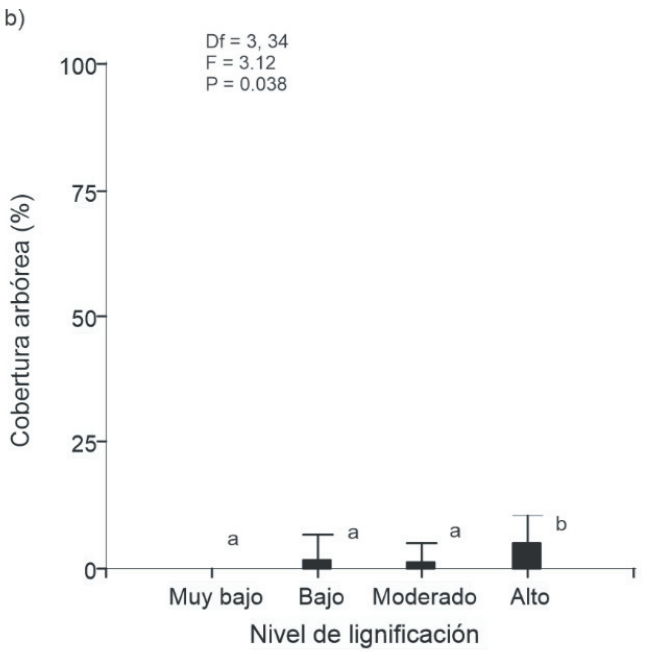

Figura 3. Gráficos de barras (medias + D.E.) para las variables a) cobertura arbustiva, b) cobertura arbórea y c) biomasa herbácea. Por cada variable se presentan los resultados de los análisis de varianza: $\mathrm{Df}=$ grados de libertad, $F=$ estadístico $F, \alpha=0.05$. Medias con letras comunes no son significativamente diferentes (prueba de LSD de Fisher).

Figure 3. Bar graphics (average + D.E.) for the variables a) shrub cover, b) tree cover and c) herbaceous biomass. Per each variable, the results of analysis of variances are presented. $\mathrm{Df}=$ degrees of freedom, $\mathrm{F}=\mathrm{F}$ statistical, $\alpha=0.05$. Averages with common letters are not significantly different (LSD Fisher test).

de pastoreo: hubo una asociación significativa, negativa y fuerte. 2) Atributos estructurales con factores ambientales. La frecuencia de fuego mostró las siguientes asociaciones significativas: a) negativa y moderada con las coberturas arbórea y arbustiva, y b) positiva y moderada con la biomasa herbácea. La intensidad histórica de pastoreo mostró las siguientes asociaciones significativas: a) positiva y moderada con las coberturas arbórea y arbustiva y b) negativa y fuerte con la biomasa herbácea. 3) Hierbas y gramíneas con factores ambientales. La frecuencia de fuego mostró una asociación significativa, positiva y moderada con las gramíneas. La intensidad histórica de pastoreo tuvo una asociación significativa, negativa y fuerte con las gramíneas. 4) Gramíneas perennes y anuales con factores ambientales. La frecuencia de fuego tuvo una asociación significativa, positiva y moderada con las gramíneas perennes. La intensidad histórica de pastoreo mostró una asociación significativa, 
Tabla 1. Porcentaje de similitud en la composición de especies (índice Chao-Sorensen) entre pares de niveles de lignificación. Entre paréntesis se indican las clases de similitud: 0-39.9\% (baja), 40-69.9\% (moderada) y 70-100\% (alta).

Table 1. Similarity percentage of species composition (Chao-Sorensen index) among pairs of woody encroachment levels. The similarity classes are indicated in parentheses: 0-39.9\% (low), 40-69.9\% (medium) and 70-100\% (high).

\begin{tabular}{llcc}
\hline & & \multicolumn{2}{c}{ Índice de similitud Chao-Sorensen } \\
& & \multicolumn{2}{c}{} \\
\hline Nivel de lignificación & Nivel de lignificación & Leñosas & Gramíneas \\
Muy bajo & Bajo & 94 (alta) & 83.6 (alta) \\
Muy bajo & Moderado & 92.7 (alta) & 79.5 (alta) \\
Muy bajo & Alto & 83.3 (alta) & 63.6 (moderada) \\
Bajo & Moderado & 94.4 (alta) & 100 (alta) \\
Bajo & Alto & 96.7 (alta) & 84.5 (alta) \\
Moderado & Alto & 98.3 (alta) & 92.6 (alta) \\
\hline
\end{tabular}

Tabla 2. Matriz de correlación entre atributos estructurales y funcionales y factores ambientales, en formato tabular.

Table 2. Correlation matrix among structural and functional attributes and environmental factors, in table format.

\begin{tabular}{|c|c|c|c|c|}
\hline Variable (1) & Variable (2) & $\begin{array}{c}\text { Coef. } \\
\text { Spearman }\end{array}$ & $\begin{array}{c}\mathrm{P}- \\
\text { valor }\end{array}$ & Fortaleza \\
\hline Frecuencia de fuego & Intensidad histórica de pastoreo & -0.71 & 0.000 & Fuerte \\
\hline Frecuencia de fuego & Cobertura arbustiva & -0.67 & 0.001 & Moderada \\
\hline Frecuencia de fuego & Cobertura arbórea & -0.59 & 0.003 & Moderada \\
\hline Frecuencia de fuego & Biomasa herbácea & 0.63 & 0.001 & Moderada \\
\hline Frecuencia de fuego & Gramíneas & 0.60 & 0.003 & Moderada \\
\hline Frecuencia de fuego & Hierbas (hoja ancha) & 0.15 & 0.485 & Muy débil \\
\hline Frecuencia de fuego & Gramíneas anuales & 0.21 & 0.339 & Débil \\
\hline Frecuencia de fuego & Gramíneas perennes & 0.60 & 0.003 & Moderada \\
\hline Frecuencia de fuego & Gramíneas palatables & 0.60 & 0.003 & Moderada \\
\hline Frecuencia de fuego & Gramíneas poco palatables & -0.16 & 0.463 & Muy débil \\
\hline Frecuencia de fuego & Gramíneas tolerantes a la sombra & 0.34 & 0.108 & Débil \\
\hline Frecuencia de fuego & Gramíneas intolerantes a la sombra & 0.51 & 0.012 & Moderada \\
\hline Frecuencia de fuego & Gramíneas con tolerancia alta al fuego & 0.64 & 0.001 & Moderada \\
\hline Frecuencia de fuego & Gramíneas con tolerancia media-baja al fuego & 0.04 & 0.854 & Muy débil \\
\hline Intensidad histórica de pastoreo & Cobertura arbustiva & 0.43 & 0.044 & Moderada \\
\hline Intensidad histórica de pastoreo & Cobertura arbórea & 0.43 & 0.048 & Moderada \\
\hline Intensidad histórica de pastoreo & Biomasa herbácea & -0.71 & 0.000 & Fuerte \\
\hline Intensidad histórica de pastoreo & Gramíneas & -0.71 & 0.000 & Fuerte \\
\hline Intensidad histórica de pastoreo & Hierbas (hoja ancha) & -0.30 & 0.175 & Débil \\
\hline Intensidad histórica de pastoreo & Gramíneas anuales & -0.01 & 0.959 & Muy débil \\
\hline Intensidad histórica de pastoreo & Gramíneas perennes & -0.71 & 0.000 & Fuerte \\
\hline Intensidad histórica de pastoreo & Gramíneas palatables & -0.71 & 0.000 & Fuerte \\
\hline Intensidad histórica de pastoreo & Gramíneas poco palatables & 0.39 & 0.074 & Débil \\
\hline Intensidad histórica de pastoreo & Gramíneas tolerantes a la sombra & -0.72 & 0.000 & Fuerte \\
\hline Intensidad histórica de pastoreo & Gramíneas intolerantes a la sombra & -0.54 & 0.009 & Moderada \\
\hline Intensidad histórica de pastoreo & Gramíneas con tolerancia alta al fuego & -0.61 & 0.002 & Moderada \\
\hline Intensidad histórica de pastoreo & Gramíneas con tolerancia media-baja al fuego & -0.50 & 0.018 & Moderada \\
\hline Cobertura arbustiva & Cobertura arbórea & 0.31 & 0.148 & Débil \\
\hline Cobertura arbustiva & Biomasa herbácea & -0.42 & 0.045 & Moderada \\
\hline Cobertura arbustiva & Gramíneas & -0.42 & 0.046 & Moderada \\
\hline Cobertura arbustiva & Hierbas (hoja ancha) & 0.08 & 0.725 & Muy débil \\
\hline Cobertura arbustiva & Gramíneas anuales & -0.17 & 0.440 & Muy débil \\
\hline Cobertura arbustiva & Gramíneas perennes & -0.42 & 0.046 & Moderada \\
\hline Cobertura arbustiva & Gramíneas palatables & -0.42 & 0.045 & Moderada \\
\hline Cobertura arbustiva & Gramíneas poco palatables & -0.15 & 0.490 & Muy débil \\
\hline Cobertura arbustiva & Gramíneas tolerantes a la sombra & -0.13 & 0.551 & Muy débil \\
\hline Cobertura arbustiva & Gramíneas intolerantes a la sombra & -0.4 & 0.055 & Moderada \\
\hline Cobertura arbustiva & Gramíneas con tolerancia alta al fuego & -0.54 & 0.007 & Moderada \\
\hline Cobertura arbustiva & Gramíneas con tolerancia media-baja al fuego & 0.04 & 0.849 & Muy débil \\
\hline Cobertura arbórea & Biomasa herbácea & -0.36 & 0.096 & Débil \\
\hline Cobertura arbórea & Gramíneas & -0.39 & 0.067 & Débil \\
\hline Cobertura arbórea & Hierbas (hoja ancha) & 0.08 & 0.706 & Muy débil \\
\hline Cobertura arbórea & Gramíneas anuales & -0.37 & 0.082 & Débil \\
\hline Cobertura arbórea & Gramíneas perennes & -0.39 & 0.067 & Débil \\
\hline Cobertura arbórea & Gramíneas palatables & -0.39 & 0.066 & Débil \\
\hline Cobertura arbórea & Gramíneas poco palatables & 0.05 & 0.806 & Muy débil \\
\hline Cobertura arbórea & Gramíneas tolerantes a la sombra & -0.45 & 0.033 & Moderada \\
\hline Cobertura arbórea & Gramíneas intolerantes a la sombra & -0.25 & 0.253 & Débil \\
\hline Cobertura arbórea & Gramíneas con tolerancia alta al fuego & -0.55 & 0.007 & Moderada \\
\hline Cobertura arbórea & Gramíneas con tolerancia media-baja al fuego & -0.15 & 0.480 & Muy débil \\
\hline
\end{tabular}


Tabla 2. Continuación.

Table 2. Continuation.

\begin{tabular}{|c|c|c|c|c|}
\hline Variable (1) & Variable (2) & $\begin{array}{c}\text { Coef. } \\
\text { Spearman }\end{array}$ & P-valor & Fortaleza \\
\hline Biomasa herbácea & Gramíneas & 0.94 & 0.000 & Muy fuert \\
\hline Biomasa herbácea & Hierbas (hoja ancha) & 0.38 & 0.072 & Débil \\
\hline Biomasa herbácea & Gramíneas anuales & 0.22 & 0.304 & Débil \\
\hline Biomasa herbácea & Gramíneas perennes & 0.94 & 0.000 & Muy fuerte \\
\hline Biomasa herbácea & Gramíneas palatables & 0.95 & 0.000 & Muy fuerte \\
\hline Biomasa herbácea & Gramíneas poco palatables & 0.07 & 0.753 & Muy débil \\
\hline Biomasa herbácea & Gramíneas tolerantes a la sombra & 0.64 & 0.003 & Moderada \\
\hline Biomasa herbácea & Gramíneas intolerantes a la sombra & 0.92 & 0.000 & Muy fuerte \\
\hline Biomasa herbácea & Gramíneas con tolerancia alta al fuego & 0.66 & 0.001 & Moderada \\
\hline Biomasa herbácea & Gramíneas con tolerancia media-baja al fuego & 0.10 & 0.662 & Muy débil \\
\hline Gramíneas & Hierbas (hoja ancha) & 0.19 & 0.376 & Muy débil \\
\hline Gramíneas & Gramíneas anuales & 0.09 & 0.677 & Muy débil \\
\hline Gramíneas & Gramíneas perennes & 1.00 & 0.000 & Muy fuerte \\
\hline Gramíneas & Gramíneas palatables & 1.00 & 0.000 & Muy fuerte \\
\hline Gramíneas & Gramíneas poco palatables & 0.04 & 0.849 & Muy débil \\
\hline Gramíneas & Gramíneas tolerantes a la sombra & 0.72 & 0.000 & Fuerte \\
\hline Gramíneas & Gramíneas intolerantes a la sombra & 0.86 & 0.000 & Fuerte \\
\hline Gramíneas & Gramíneas con tolerancia alta al fuego & 0.77 & 0.000 & Fuerte \\
\hline Gramíneas & Gramíneas con tolerancia media-baja al fuego & 0.27 & 0.213 & Débil \\
\hline Hierbas (hoja ancha) & Gramíneas anuales & -0.13 & 0.544 & Muy débil \\
\hline Hierbas (hoja ancha) & Gramíneas perennes & 0.19 & 0.376 & Muy débil \\
\hline Hierbas (hoja ancha) & Gramíneas palatables & 0.20 & 0.352 & Débil \\
\hline Hierbas (hoja ancha) & eas poco palatables & -0.24 & 0.266 & Débil \\
\hline Hierbas (hoja ancha) & Gramíneas tolerantes a la sombra & 0.05 & 0.813 & Muy débi \\
\hline Hierbas (hoja ancha) & Gramíneas intolerantes a la sombra & 0.35 & 0.100 & Débil \\
\hline Hierbas (hoja & Gramíneas con tolera & 0.00 & 0.986 & Muy débil \\
\hline Hierb & al fuego & -0.01 & 0.961 & Muy débil \\
\hline Gramíneas anuales & Gramíneas perennes & 0.09 & 0.677 & Muy débil \\
\hline Gramíneas anuales & Gramíneas palatables & 0.09 & 0.677 & Muy débil \\
\hline Gramíneas anuales & as poco palatables & 0.56 & 0.005 & Moderada \\
\hline Gramíneas anuales & es a la sombra & 0.07 & 0.739 & Muy débil \\
\hline Gramí & es a la sombra & 0.26 & 0.238 & Débil \\
\hline Gramíneas anuales & neas con tolerancia alta al fuego & 0.05 & 0.837 & Muy débil \\
\hline Gramíneas ar & media-baja al fuego & -0.45 & 0.030 & Moderada \\
\hline is perennes & s palatables & 1.00 & 0.000 & Muy fuerte \\
\hline Gramíneas perennes & Gramíneas poco palatables & 0.04 & 0.849 & Muy débil \\
\hline eas perennes & tes a la sombra & 0.72 & 0.000 & Fuerte \\
\hline Gramíneas perennes & Gramíneas intolerantes a la sombra & 0.86 & 0.000 & Fuerte \\
\hline Gram & alta al fuego & 0.77 & 0.000 & Fuerte \\
\hline Gramí & media-baja al fuego & 0.27 & 0.213 & Débil \\
\hline Gramíneas palatables & Gramíneas poco palatables & 0.04 & 0.868 & Muy débi \\
\hline Gramíneas palatables & eas tolerantes a la sombra & 0.72 & 0.000 & Fuerte \\
\hline Gramíneas $\mathrm{p}$ & neas intolerantes a la sombra & 0.86 & 0.000 & Fuerte \\
\hline neas palatables & as con tolerancia alta al fuego & 0.77 & 0.000 & Fuerte \\
\hline Gramíneas palatables & Gramíneas con tolerancia media-baja al fuego & 0.27 & 0.219 & Débil \\
\hline Gramíneas poco palatables & Gramíneas tolerantes a la sombra & -0.19 & 0.397 & Muy débil \\
\hline Gramíneas poco palatables & Gramíneas intolerantes a la sombra & 0.15 & 0.504 & Muy débil \\
\hline Gramíneas poco palatables & íneas con tolerancia alta al fuego & -0.01 & 0.963 & Muy débil \\
\hline Gramíneas poco palatables & Gramíneas con tolerancia media-baja al fuego & -0.53 & 0.009 & Moderada \\
\hline Gramíneas tolerantes a la sombra & eas intolerantes a la sombra & 0.42 & 0.047 & Moderada \\
\hline Gramíneas tolerantes a la sombra & Gramíneas con tolerancia alta al fuego & 0.46 & 0.026 & Moderada \\
\hline Gramíneas tolerantes a la sombra & Gramíneas con tolerancia media-baja al fuego & 0.58 & 0.003 & Moderada \\
\hline & Gramíneas con tolerancia alta al fuego & 0.62 & 0.001 & Moderada \\
\hline \multirow{2}{*}{$\begin{array}{l}\text { Gramíneas intolerantes a la sombra } \\
\text { Gramíneas con tolerancia alta al } \\
\text { fuego }\end{array}$} & Gramíneas con tolerancia media-baja al fuego & -0.01 & 0.980 & Muy débil \\
\hline & Gramíneas con tolerancia media-baja al fuego & 0.17 & 0.436 & Muy débil \\
\hline
\end{tabular}

negativa y fuerte con las gramíneas perennes. 5) Gramíneas según su palatabilidad con factores ambientales. La frecuencia de fuego tuvo una asociación significativa, positiva y moderada con las gramíneas palatables. La intensidad histórica de pastoreo tuvo una asociación significativa, negativa y fuerte con las gramíneas palatables. 6) Gramíneas según su tolerancia a la sombra con factores ambientales. La frecuencia de fuegos, tuvo una asociación significativa, positiva y moderada con las gramíneas intolerantes a la sombra. La intensidad histórica de pastoreo mostró las siguientes asociaciones significativas: a) negativa y fuerte con las gramíneas tolerantes a la sombra y b) negativa y moderada con las gramíneas intolerantes a la sombra. 7) Gramíneas según su tolerancia al fuego con 

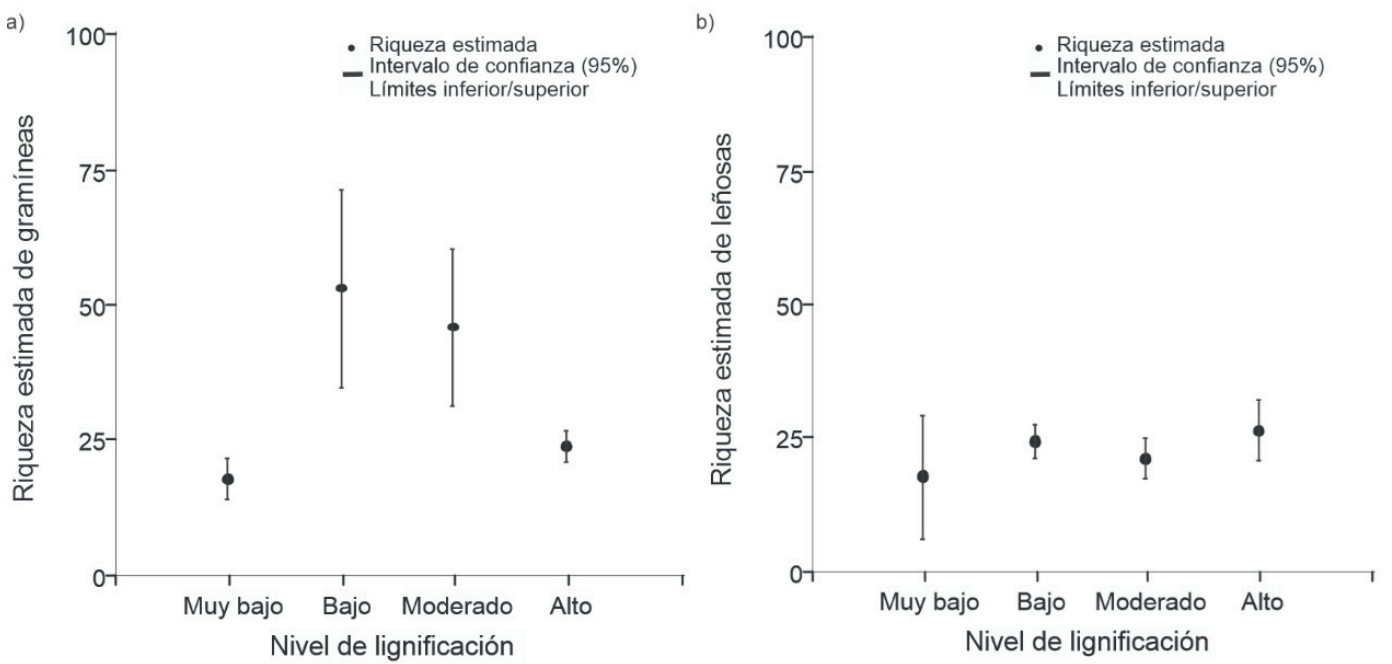

Figura 4. Estimación de la riqueza acumulada de especies e intervalos de confianza a partir del método de rarefacción y extrapolación. a) Gramíneas; b) Leñosas.

Figure 4. Estimation of species accumulated richness and confidence interval through the rarefaction and extrapolation method. a) Grass species; b) Woody species.

factores ambientales. La frecuencia de fuego mostró una asociación significativa, positiva y moderada con las gramíneas con tolerancia alta al fuego. La intensidad histórica de pastoreo, tuvo una asociación significativa, negativa y moderada con las gramíneas con tolerancia media-baja y alta al fuego.

En el Material Suplementario D se presenta una estadística descriptiva complementaria de los diferentes tipos funcionales de plantas.

\section{Discusión}

\section{Gradiente de lignificación y estructura de la vegetación}

Un análisis de casos a nivel mundial mostró que, consistentemente, la cobertura arbustiva aumenta y la cobertura herbácea decrece con la lignificación, mientas que la cobertura arbórea exhibe respuestas variables (Eldridge et al. 2011). En acuerdo con la predicción 1, nuestros resultados sugirieron que la lignificación de los pastizales/sabanas se explicaría fundamentalmente por incrementos sustanciales en la cobertura arbustiva (i.e., en promedio, la cobertura arbustiva, pasó de $15.8 \%$ en el nivel de lignificación muy bajo a $88.9 \%$ en el nivel de lignificación alto), mientras que la cobertura arbórea sería mínima y tendría un rol menor (i.e., en promedio, la cobertura arbórea representó $0 \%, 4.7 \%, 2.3 \%$ y $5.4 \%$ de la cobertura leñosa total, respectivamente, en los niveles de lignificación muy bajo, bajo, moderado y alto). La dominancia de los arbustos que observamos concuerda con un estudio realizado en sitios ecológicos bajos del Campo Experimental F. Cantos (INTA Santiago del Estero), donde los pastizales/sabanas lignificados tuvieron una muy alta cobertura arbustiva (91.5\%, en promedio) y una baja cobertura arbórea (23.9\%, en promedio) (Coria et al. 2016). En el Chaco Semiárido de la provincia de Salta, leñosas colonizadoras comunes como $A$. quebracho-blanco, P. nigra y S. mistol, con el tiempo (aproximadamente más de 50 años), adoptan porte arbóreo y transforman la fisonomía de arbustal en una de bosque bajo (Morello and Saravia Toledo 1959). En nuestro estudio, en promedio entre todas las unidades de muestreo, $P$. nigra ocupó el segundo lugar (55.8 contactos/transecta), A. quebracho-blanco, el séptimo (20.2 contactos/transecta) y S. mistol, el décimo (9.1 contactos/transecta), indicando que fueron especies comunes, y de no mediar disturbios antrópicos o naturales que limiten el crecimiento de los individuos (e.g., mecánicos, fuego, enfermedades), existiría un potencial para que los arbustales más antiguos evolucionen a bosques de baja altura.

Consistente también con la predicción 1 , la significativa menor biomasa herbácea observada en el nivel de lignificación alto (57.7\% menor respecto al nivel de lignificación muy bajo) se relacionaría con el efecto combinado del sobrepastoreo y la competencia ejercida por la alta densidad de leñosas, que 
restringe el desarrollo de la vegetación herbácea (Bestelmeyer et al. 2003; Kunst et al. 2012; Díaz 2015) (reflejado en que la intensidad histórica de pastoreo se asoció significativa y positivamente con la cobertura arbórea y arbustiva, y significativa y negativamente con la biomasa herbácea). Nuestros resultados, sugieren que lugares con coberturas leñosas inferiores al $75 \%$, todavía tendrían potencial para producir niveles elevados de biomasa herbácea (i.e., >3000 kg MS/ha).

\section{Gradiente de lignificación y diversidad de gramíneas y leñosas}

En cualquier escala espacial, la variedad de hábitats promueve una mayor biodiversidad (Fischer et al. 2006). Consistente con la predicción 2, el pico significativo en la riqueza de gramíneas observado en los niveles de lignificación bajo y moderado se relacionaría con sus coberturas leñosas intermedias (en promedio, 39.3\% y 64\%, respectivamente) y abundante biomasa herbácea (en promedio, 4053.1 y $3279.7 \mathrm{~kg}$ MS/ha, respectivamente), que habrían determinado que tanto el hábitat leñoso como herbáceo estuviesen bien representados (Archer et al. 2017).

Consistente con la predicción 3, la similitud más baja en la composición de gramíneas entre los niveles de lignificación muy bajo y alto se vincularía a que a medida que progresa la lignificación, las especies adaptadas a pastizales/sabanas decrecen y las adaptadas a arbustales/bosques aumentan (Archer et al. 2017), lo que habría maximizado la disimilitud en la composición de especies entre estos extremos del gradiente de lignificación. Al respecto, nuestros resultados, sugieren que a) en el nivel de lignificación muy bajo, las gramíneas adaptadas a pastizales/sabanas (i.e., intolerantes a la sombra) tendieron a dominar a las gramíneas adaptadas a arbustales/ bosques (i.e., tolerantes a la sombra), dado que aportaron el $68.8 \%$ de las especies (11) y el 70.4 $\%$ de la biomasa (2952.4 kg MS/ha) y b) en el nivel de lignificación alto, en comparación a la situación anterior, las gramíneas adaptadas a pastizales/sabanas tendieron a aportar menos especies $(60.9 \%, 14)$ y biomasa $(41.8 \%, 631.4$ $\mathrm{kg}$ MS/ha). En el interior de los arbustales, las gramíneas adaptadas a pastizales/sabanas comúnmente subsisten en microhábitats desprovistos de cobertura leñosa (pequeños claros).
La riqueza de leñosas fue uniforme a lo largo del gradiente de lignificación, lo cual fue consistente con un análisis de casos a nivel mundial, que mostró que la riqueza de arbustos y árboles tiende a no modificarse significativamente con la lignificación (Eldridge et al. 2011). Por otra parte, las similitudes en la composición de leñosas entre todos los pares del gradiente de lignificación se interpretaron como altas en todos los casos (índice Chao-Sorensen $\geq 83.3 \%$ ) (Tabla 1). Por lo tanto, la composición de leñosas fue además bastante uniforme a lo largo del gradiente de lignificación. Nuestros resultados sugieren que tanto la riqueza como la composición de leñosas serían atributos poco afectados por la lignificación, lo cual no es consistente con las predicciones 2 y 3 .

Una interpretación relevante derivada de los resultados anteriores es que la lignificación se debería principalmente a incrementos en las abundancias de especies leñosas presentes y no al arribo de nuevas especies desde otros lugares, poniendo de manifiesto la importancia de los mecanismos de dispersión de las especies. En nuestro estudio predominaron especies que dispersan sus semillas a través de algún agente: aves (C. atamisquea, C. ehrenbergiana, C. microphylla y Schinus sp.), aves y hormigas (J. rhombifolia), hormigas ( $P$. sericantha), mamíferos domésticos y silvestres (V. aroma, C. coccinea, G. decorticans, M. carinatus, O. quimilo, $P$. alba, P. nigra, $S$. mistol y X. Americana), y viento (A. quebrachoblanco, C. praecox, L. divaricata, S. lorentzii y $A$. gratissima) (Morello and Saravia Toledo 1959; Abraham de Noir and Bravo 2014). Un grupo reducido de especies dispersa sus semillas sin mediar agentes (i.e., autocoria) como $S$. praecox, $M$. detinens y $S$. aphylla (Morello and Saravia Toledo 1959; Abraham de Noir and Bravo 2014), y sólo una especie se reproduce de manera predominantemente asexual ( $L$. turbinata). Desconocemos la estrategia de dispersión de J. xylosteoides.

\section{Asociaciones entre atributos estructurales y funcionales con factores ambientales}

Consistente con la predicción 4, los atributos estructurales y diversos atributos funcionales se asociaron de manera significativa con los factores ambientales considerados. En primer lugar, destacamos que hubo una serie de correlaciones significativas, coherentes con la hipótesis del sobrepastoreo. La intensidad 
histórica de pastoreo se asoció fuertemente con la reducción de la frecuencia de fuego, lo cual, a su vez, se asoció con el incremento de la cobertura arbórea y arbustiva y el decrecimiento de la biomasa herbácea (i.e., evidencia estadística que representa un aporte original de nuestro trabajo). En regiones áridas y semiáridas del mundo, los causales de la lignificación usualmente citados son el cambio climático, los niveles elevados de $\mathrm{CO}_{2^{\prime}}$ el sobrepastoreo, los cambios en la frecuencia de fuegos, los cambios en la habilidad competitiva de las pasturas, la dispersión de semillas por el ganado, la actividad de pequeños animales y las combinaciones de ellos (Van Auken 2009; D'Odorico et al. 2012; Archer et al. 2017). Sin embargo, el sobrepastoreo y la consecuente supresión de fuegos de pastizal parecen ser las razones dominantes de la lignificación en las regiones áridas y semiáridas del sudoeste de Norteamérica y otros lugares (Van Auken 2009), incluido el Chaco Semiárido (potenciado por sequías) (Morello and Saravia Toledo 1959; Morello 1970; Adamoli et al. 1972, 1990; Morello and Adamoli 1974). Por último, en el Chaco Semiárido, la inundación en lugares puntuales sujetos al desborde periódico de ríos (e.g., Bañados del Río Dulce) es otro mecanismo con gran influencia en el balance leñosas/herbáceas a favor de las herbáceas (Morello 1970; Morello and Adamoli 1974), aunque éste no es el caso de nuestra área de estudio.

El decrecimiento significativo de las gramíneas en general y de otros tipos específicos de gramíneas (i.e., perennes, palatables, tolerantes e intolerantes a la sombra y con tolerancia media-baja y alta al fuego) con el incremento en la intensidad histórica de pastoreo sugiere que el sobrepastoreo declinaría las abundancias de estas plantas. Por otra parte, la asociación entre el incremento en la intensidad histórica de pastoreo con el incremento en la cobertura arbustiva y arbórea y el decrecimiento de las gramíneas palatables concuerda con el hecho bien conocido de que el sobrepastoreo promueve la dominancia de comunidades de leñosas con pobre valor forrajero por sobre comunidades de gramíneas forrajeras (Evans et al. 2017), configurando un problema tradicional para la producción pastoril vinculado con la lignificación (Archer et al. 2017).

El sobrepastoreo puede inducir también a la dominancia de las hierbas por sobre las gramíneas (con impactos variables en los procesos del suelo dependiendo de las especies) o, en otros casos, inducir a la dominancia de las gramíneas anuales por sobre las gramíneas perennes (vinculado con problemas como la escasa a nula cobertura herbácea durante sequias, incremento de la erosión, eliminación de islas de fertilidad creado por las especies perennes, etc.) (Vetter 2005; Evans et al. 2017). En nuestro estudio, las hierbas y las gramíneas anuales no mostraron asociaciones significativas con la intensidad histórica de pastoreo (i.e., lo esperado era que se correlacionen positivamente). Asimismo, a lo largo del gradiente de lignificación, las gramíneas perennes dominaron a las hierbas y gramíneas anuales (i.e., las gramíneas perennes representaron el $89.8 \%, 87.6 \%, 82.1 \%$ y $77 \%$ de la biomasa herbácea total, respectivamente, en los niveles de lignificación muy bajo, bajo, moderado y alto). Estos resultados concuerdan con lo informado para un pastizal nativo del Chaco Árido, donde, a pesar del sobrepastoreo, las gramíneas perennes prevalecieron (Díaz 2015). Sin embargo, tanto en el Chaco Árido como en el Semiárido, el completo reemplazo de comunidades dominadas por gramíneas perennes por comunidades puras de hierbas o de gramíneas anuales con nulo valor forrajero y muy baja productividad (e.g., 0$100 \mathrm{~kg} \mathrm{MS} / \mathrm{ha}$ ) fue reportado en situaciones de degradación extrema (e.g., horizonte A del suelo eliminado) (Morello and Saravia Toledo 1959; Díaz 2015). En nuestro estudio, la prevalencia de gramíneas perennes a lo largo del gradiente de lignificación indicaría que en general nuestras unidades de muestreo no estuvieron profundamente alteradas.

El incremento significativo de las gramíneas en general y de otros tipos específicos de gramíneas (i.e., perennes, palatables, intolerantes a la sombra y con tolerancia alta al fuego) con el aumento en la frecuencia de fuego probablemente se relacione con que los fuegos recurrentes de pastizal reducen la competencia de las leñosas y estimulan la floración (en ciertas especies), la germinación y el crecimiento de las gramíneas (Allen 2008; Scott et al. 2013), lo cual también fue observado en el Chaco Semiárido (Kunst et al. 2003a). Además, las gramíneas intolerantes a la sombra y con tolerancia alta al fuego pudieron haber sido favorecidas por los fuegos frecuentes que generaron hábitats abiertos con alta disponibilidad de luz solar y decrecieron las abundancias de las especies intolerantes al fuego (Ellis et al. 1980; Everson et al. 1988; Bond et al. 2003; Foster et al. 2004). En nuestro estudio, cinco de las seis gramíneas 
intolerantes a la sombra evaluadas fueron al mismo tiempo altamente tolerantes al fuego (Material Suplementario B), lo que sugiere que, al menos para estas especies, la intolerancia a la sombra y alta tolerancia al fuego podrían ser caracteres funcionales vinculados.

\section{Hacia la restauración y uso sustentable de los pastizales/sabanas}

La lignificación junto con la conversión de ecosistemas nativos en tierras para cultivos (incluido las pasturas exóticas) fueron identificadas como las mayores causas de la desaparición de los pastizales/sabanas en la Región Chaqueña (Grau et al. 2014; Fernández et al. 2020). A la fecha, no existen experiencias destacadas en el campo de la restauración y el uso sustentable de estos ecosistemas. En gran parte, ello se debería a que las políticas de conservación de la Argentina priorizan a los bosques e ignoran a los pastizales/sabanas (Grau et al. 2014). En la comunidad científica, aunque se advierte un interés creciente por la problemática (Grau et al. 2014; Torres et al. 2014; Kunst et al. 2015; Fernández et al. 2020), resulta insuficiente dada la gravedad de la situación. Por lo tanto, es fundamental estimular a los decisores políticos para que incluyan a los pastizales/sabanas en las políticas de conservación y uso sustentable de los ecosistemas nativos, y también a la comunidad científica para que aporte los conocimientos necesarios para una toma de decisiones eficaz (Grau et al. 2014; Fernández et al. 2020).

En áreas bajo producción ganadera, la restauración de los pastizales/sabanas tendrá mayores posibilidades de éxito si se constituye, además, en una alternativa rentable económicamente. El desafío será revertir el estado de arbustal a pastizal/sabana productivo y luego mantenerlo en el tiempo. Nuestro estudio sugiere que sería apropiado un manejo orientado a reestablecer o mantener los regímenes de fuego (i.e., regulan la cobertura leñosa y favorecen a las gramíneas palatables) y pastorear racionalmente los ambientes. Sin embargo, esta sugerencia no es novedosa para la región y ya fue expresada en diversas ocasiones (Morello 1970; Morello and Adamoli 1974; Kunst et al. 2003b). El pastoreo racional se logra ajustando la carga ganadera (e.g., ha/unidad ganadera) a la cantidad de forraje herbáceo instantáneo disponible en los lotes, utilizando la metodología del 'balance forrajero' (Kunst et al. 2015).
Los fuegos prescriptos constituyen una herramienta de manejo de la vegetación en diversas partes del mundo donde el fuego representa un evento ecológico natural y de gran influencia en la dinámica del paisaje. Para ejercer un control eficiente en la cobertura de arbustos, el fuego prescripto de pastizal debe ser de alta intensidad, lo cual requiere una carga de combustible fino mayor a $3000 \mathrm{~kg} \mathrm{MS/ha} \mathrm{(Kunst} \mathrm{et} \mathrm{al.} \mathrm{2003b).}$ Nuestros resultados sugieren que en el área de estudio, las coberturas leñosas por debajo del $75 \%$ tendrían potencial para producir biomasa herbácea por encima de este umbral. En estos casos, regímenes de pastoreo racional y la aplicación de fuegos prescriptos cada 3-4 años permitirían reestablecer progresivamente $\mathrm{o}$ mantener los pastizales/sabanas como hábitats para el ganado y la flora y fauna silvestre, conservando las gramíneas palatables (Kunst et al. 2003b, 2003a). En cambio, las coberturas leñosas por encima del 75\% no producirían biomasa herbácea más allá del umbral de los $3000 \mathrm{~kg}$ MS/ha y, por ende, los fuegos de pastizal intensos no podrían ocurrir. En estos casos, el restablecimiento del pastizal/sabana se podría acelerar mediante regímenes de disturbios que utilicen en secuencia 1) rolado de baja intensidad (i.e., disturbio mecánico) para disminuir la competencia de los arbustos, minimizando la generación de residuos leñosos gruesos que incrementan el riesgo de incendios severos, 2) supresión del pastoreo por una o dos estaciones de crecimiento para promover la acumulación de biomasa herbácea, y 3) fuegos prescriptos de pastizal para disminuir aún más la competencia de los arbustos y favorecer nuevamente a la vegetación herbácea (Kunst et al. 2003b, 2008). Por último, cuando la degradación es extrema, lo más probable es que las gramíneas palatables perennes nativas hayan desaparecido y perdido viabilidad en el banco de semillas del suelo, por lo cual, tratamientos como rolados y supresión del pastoreo no se traducirían en incrementos satisfactorios en la biomasa de estas gramíneas, siendo necesario recurrir a su siembra (Kunst et al. 2008; Díaz 2015; Puthod et al. 2020).

Desde sus inicios, la ganadería en el Chaco Semiárido se sustentó en las gramíneas nativas, que siguen siendo muy utilizadas. Sin embargo, en la actualidad se utilizan intensamente gramíneas forrajeras de origen africano, cuyas semillas se adquieren fácilmente en el mercado. Las variedades más usadas pertenecen a las especies Megathyrsus maximus, Cenchrus ciliaris y Chloris gayana 
(Díaz 2015). Es común que se apliquen disturbios mecánicos a la vegetación leñosa y las gramíneas exóticas se siembran en simultáneo; así se obtienen incrementos en la productividad del forraje herbáceo de hasta 400-500\% (Fumagalli and Kunst 2002). El desafío será encontrar la manera en que la restauración de los pastizales/sabanas se complemente y coexista con estas alternativas de manejo altamente productivas. Se ha enfatizado en que el empleo de gramíneas exóticas se debe restringir a los sectores más degradados de los predios productivos, dado que los pastizales naturales bien manejados son rentables (Díaz 2015). Otra manera para incrementar satisfactoriamente la oferta de forraje herbáceo, pero de modo más amigable con el ambiente, sería utilizar variedades comerciales de herbáceas forrajeras nativas (i.e., gramíneas, leguminosas y otras latifoliadas) adaptadas a la heterogeneidad ambiental de los ecosistemas chaqueños (Díaz 2015; Pensiero et al. 2017). Sin embargo, este aspecto aún no logra consolidarse en la región y la forma para proveerse de semillas de herbáceas nativas es cosecharlas en el campo (Díaz 2015; Pensiero et al. 2017). A la fecha, existe una única variedad de pastura forrajera nativa desarrollada, denominada Chamical INTA y perteneciente a la especie T. crinita (presente en nuestro estudio y común en todo el Chaco Árido y Semiárido), que se destaca por su buen potencial forrajero, su adaptación a suelos salinos y arcillosos, y su tolerancia al frío y a la sequía (Ledesma et al. 2017), aunque aspectos vinculados con la producción de semilla aún se hallan en fase de desarrollo tecnológico.

\section{Conclusiones}

En relación con la primera pregunta, nuestros resultados sugirieron que: a) la lignificación se debería básicamente a incrementos sustanciales en la cobertura arbustiva, mientras que la cobertura arbórea tendría un rol menor, $b$ ) disminuciones significativas en la productividad de la biomasa herbácea ocurrirían con niveles altos de lignificación, c) la máxima riqueza de gramíneas sucedería en niveles intermedios de lignificación, d) la máxima disimilitud en la composición de gramíneas ocurriría entre niveles muy bajos y altos de lignificación, y e) la riqueza y la composición de leñosas serían poco afectadas por la lignificación.

En cuanto a nuestra segunda pregunta, obtuvimos evidencia estadística a favor de la hipótesis del sobrepastoreo, en base a que el incremento en la intensidad histórica de pastoreo se asoció de manera significativa y fuerteconla reducción enla frecuencia defuego, lo que, a su vez, se asoció significativamente con el incremento en la cobertura arbórea y arbustiva y el decrecimiento en la biomasa herbácea. Los resultados sugirieron también que 1) el incremento en la intensidad histórica de pastoreo se asociaría con el decrecimiento de las gramíneas en general y de otros tipos específicos de gramíneas (i.e., perennes, palatables, tolerantes e intolerantes a la sombra y con tolerancia media-baja y alta al fuego), 2) la falta de asociación entre la intensidad histórica de pastoreo con las hierbas y las gramíneas anuales se debería a que estos tipos funcionales dominan en condiciones de degradación extrema (que no sería el caso de nuestro estudio), y 3) el incremento en la frecuencia de fuego se asociaría con el incremento de las gramíneas en general y de otros tipos específicos de gramíneas (i.e., perennes, palatables, intolerantes a la sombra y con tolerancia alta al fuego).

Agradecimientos. Agradecemos a E. Monti, H. Pérez y J. Godoy, personal y ex personal del INTA EEA Santiago del Estero, quienes participaron en los muestreos de campo durante la década de los 90. A Guillermo Debandi (INTA EEA Junín) y César Massi (Vivero "El Tala") por su aporte de información sobre la dispersión de especies leñosas. A H. Van Meer (INTA EEA Santiago del Estero) y M. E. Periago (Fundación Vida Silvestre Argentina) por la revisión del idioma inglés. A tres revisores anónimos, por su contribución a la mejora del manuscrito.

\section{REFERENCIAS}

Abraham de Noir, F., and S. Bravo. 2014. Frutos de leñosas nativas de Argentina: Parte I. Chaco Occidental y Serrano. First edition. Facultad de Ciencias Forestales. Universidad Nacional de Santiago del Estero, Santiago del Estero.

Abril, A., and E. Bucher. 1999. The effects of overgrazing on soil microbial community and fertility in the Chaco dry savannas of Argentina. Applied Soil Ecology 12:159-167. https://doi.org/10.1016/S0929-1393(98)00162-0.

Adamoli, J., R. Neumann, and A. D. Ratier Colina. 1972. El chaco aluvional salteño (Convenio INTA-Provincia de Salta). Revista de Investigaciones Agropecuarias. Serie 3 Clima y Suelo 9:165-237. 
Adamoli, J., E. Sennhauser, J. M. Acero, and A. Rescia. 1990. Stress and Disturbance: Vegetation Dynamics in the Dry Chaco Region of Argentina. Journal of Biogeography 17:491-500. https://doi.org/10.2307/2845381.

Allen, H. 2008. Fire: plant functional types and patch mosaic burning in fire-prone ecosystems. Progress in Physical Geography 32:421-437. https://doi.org/10.1177/0309133308096754.

Angueira, C. 2007. Carta de Suelos y Evaluación de Tierras Tapso-Lavalle-Frías. INTA - Estación Experimental Agropecuaria Santiago del Estero, Santiago del Estero. Pp. 99.

Angueira, C., D. Prieto, J. López, and G. Barraza. 2007. Sistema de Información Geográfica de Santiago del Estero (SigSE 2.0). Instituto Nacional de Tecnología Agropecuaria, Argentina.

Angueira, C., and J. Vargas Gil. 1993. Suelos de Lavalle, Tapso y Frías. INTA EEA Santiago del Estero.

Archer, S. R., E. M. Andersen, K. I. Predick, S. Schwinning, R. J. Steidl, and S. R. Woods. 2017. Woody plant encroachment: causes and consequences. Pp. 25-84 in D. D. Briske (ed.). Rangeland Systems. Processes, Management and Challenges. Springer, Cham, Switzerland. https://doi.org/10.1007/978-3-319-46709-2_2.

Bestelmeyer, B. T., J. R. Brown, K. M. Havstad, R. Alexander, G. Chavez, and J. E. Herrick. 2003. Development and Use of State-and-Transition Models for Rangelands. Journal of Range Management 56:114-126. https://doi.org/10.2307/ 4003894.

Boletta, P. 1998. Clima. Pp. 7-21 in R. Casas (ed.). Desmonte y habilitación de tierras en la región chaqueña semiárida. FAO, Santiago, Chile.

Bond, W. J., G. F. Midgley, and F. I. Woodward. 2003. The importance of low atmospheric CO2 and fire in promoting the spread of grasslands and savannas. Global Change Biology 9:973-982. https://doi.org/10.1046/j.13652486.2003.00577.x.

Bucher, E. H. 1982. Chaco and Caatinga - South American Arid Savannas, Woodlands and Thickets. In B. J. Huntley et al. (eds.). Ecology of Tropical Savannas. Springer-Verlag, Berlin. https://doi.org/10.1007/978-3-642-68786-0_4.

Chebez, J. C. 2008. Los que se van: mamíferos. Editorial Albatros, Buenos Aires, Argentina.

Colwell, R. K. 2013. EstimateS: Statistical estimation of species richness and shared species from samples. Version 9. User's Guide.

Coria, R. D., O. R. Coria, and C. R. Kunst. 2016. Diversidad y composición de especies de aves en un gradiente bosque-arbustal-sabana del Chaco Semiárido, Argentina. Ornitología Neotropical 27:1-15. https://doi.org/10.25260/ EA.17.27.1.0.280

Di Rienzo, J. A., F. Casanoves, M. G. Balzarini, L. González, M. Tablada, and C. W. Robledo. 2013. Infostat versión 2013. Grupo Infostat, FCA, Universidad Nacional de Córdoba, Argentina.

Díaz, R. O. 2015. Utilización de pastizales naturales. First edition. Encuentro Grupo Editor.

Díaz, S. M., D. E. Gurvich, N. Pérez Harguindeguy, and M. R. Cabido. 2002. ¿Quién necesita los tipos funcionales de plantas? Sociedad Argentina de Botánica 37:135-140.

D'Odorico, P., G. S. Okin, and B. T. Bestelmeyer. 2012. A synthetic review of feedbacks and drivers of shrub encroachment in arid grasslands. Ecohydrology 5:520-530. https://doi.org/10.1002/eco.259.

Eldridge, D. J., M. A. Bowker, F. T. Maestre, E. Roger, J. F. Reynolds, and W. G. Whitford. 2011. Impacts of shrub encroachment on ecosystem structure and functioning: towards a global synthesis. Ecology Letters 14:709-722.

Eldridge, D. J., M. Delgado-Baquerizo, S. K. Travers, J. Val, and I. Oliver. 2017. Do grazing intensity and herbivore type affect soil health? Insights from a semi-arid productivity gradient. Journal of Applied Ecology 54:976-985. https: //doi.org/10.1111/1365-2664.12834.

Ellis, R., J. Vogel, and A. Fuls. 1980. Photosynthetic pathways and the geographical distribution of grasses in South West Africa/Namibia. South African Journal of Science 76:307-314.

Evans, R. D., R. A. Gill, V. T. Eviner, and V. Bailey. 2017. Soil and belowground processes. Pp. 131-168 in D. D. Briske (ed.). Rangeland Systems. Processes, Management and Challenges. Springer, Cham, Switzerland. https://doi.org/ 10.1007/978-3-319-46709-2_4.

Everson, C. S., T. M. Everson, and N. M. Tainton. 1988. Effects of intensity and height of shading on the tiller initiation of six grass species from the Highland sourveld of Natal. South African Journal of Botany 54:315-318. https://doi.org/ 10.1016/S0254-6299(16)31297-2.

Fernández, P. D., M. Baumann, G. Baldi, N. R. Banegas, S. Bravo, I. N. Gasparri, M. Lucherini, S. Marinaro, S. A. Nanni, J. A. Nasca, T. Tessi, and R. H. Grau. 2020. Grasslands and Open Savannas of the Dry Chaco. Pp. 562-576 in M. I. Goldstein and D. A. Della Sala (eds.). Encyclopedia of the World's Biomes. Elsevier, Oxford. https://doi.org/10.1016/ B978-0-12-409548-9.12094-9.

Fischer, J., D. B. Lindenmayer, and A. D. Manning. 2006. Biodiversity, ecosystem function, and resilience: ten guiding principles for commodity production landscapes. Frontiers in Ecology and the Environment 4:80-86. https://doi.org/ 10.1890/1540-9295(2006)004[0080:BEFART]2.0.CO;2.

Foster, B. L., T. L. Dickson, C. A. Murphy, I. S. Karel, and V. H. Smith. 2004. Propagule pools mediate community assembly and diversity-ecosystem regulation along a grassland productivity gradient. Journal of Ecology 92:435-449. https://doi.org/10.1111/j.0022-0477.2004.00882.x.

Fowler, J., and L. Cohen. 1990. Practical statistics for field biology. John Wiley and Sons, New York.

Fumagalli, A., and C. Kunst. 2002. Producción de carne vacuna en el NOA: cómo mejorar la oferta forrajera de los sistemas de cría. IDIA XXI Revista de información sobre investigación y desarrollo agropecuario 2:73-78.

Gastó, J., F. Cosio, and D. Panario. 1993. Clasificación de ecorregiones y determinación de sitio y condición, Manual 
de aplicación a municipios y predios rurales. Red de Pastizales Andinos (REPAAN), Santiago, Chile.

Gastó, J., F. Silva, and F. Cosio. 1990. Sistema de Clasificación de Pastizales de Sudamérica. Sistema en Agricultura. IISA 9.

Grau, H. R., R. Torres, N. I. Gasparri, P. G. Blendinger, S. Marinaro, and L. Macchi. 2014. Natural grasslands in the Chaco. A neglected ecosystem under threat by agriculture expansion and forest-oriented conservation policies. Journal of Arid Environments 123:40-46. https://doi.org/10.1016/j.jaridenv.2014.12.006.

Holechek, J. L., H. Gómez, F. Molinar, and D. Galt. 1999. Grazing studies: what we've learned. Rangelands Archives 21:12-16.

Instituto de Botánica Darwinion. 2017. Flora Argentina. Plantas Vasculares de la República Argentina. URL: floraargentina.edu.ar.

Iriondo, M. 1993. Geomorphology and late Quaternary of the Chaco (South America). Geomorphology 7:289-303. https: //doi.org/10.1016/0169-555X(93)90059-B.

Kunst, C., S. Bravo, F. Moscovich, J. Herrera, J. Godoy, and S. Vélez. 2003a. Fecha de aplicación de fuego y diversidad de herbáceas en una sabana de Elionorus muticus (Spreng) O. Kuntze. Revista Chilena de Historia Natural 76:105-115. https://doi.org/10.4067/S0716-078X2003000100010.

Kunst, C., S. Bravo, and J. L. Panigatti (eds.). 2003b. Fuego en los ecosistemas argentinos. Ediciones INTA, Santiago del Estero.

Kunst, C., M. Ledesma, E. Monti, J. Casillo, and J. Godoy. 2007. Gramíneas indicadores de condición en sitios de pastizal del sudoeste de Santiago del Estero. Revista de Investigaciones Agropecuarias 36:33-61.

Kunst, C., R. Ledesma, S. Bravo, A. Albanesi, A. Anriquez, H. van Meer, and J. Godoy. 2012. Disrupting woody steady states in the Chaco region (Argentina): Responses to combined disturbance treatments. Ecological Engineering 42 : 42-53. https://doi.org/10.1016/j.ecoleng.2012.01.025.

Kunst, C., E. Monti, H. Pérez, and J. Godoy. 2006. Assessment of the rangelands of southwestern Santiago del Estero, Argentina, for grazing management and research. Journal of Environmental Management 80:248-265. https://doi.org/ 10.1016/j.jenvman.2005.10.001.

Kunst, C., M. Navall, R. D. Coria, R. Ledesma, P. Tomsic, A. González, A. Gómez, and D. Feuillade. 2015. Guía de Prácticas Recomendables para Sistemas Silvopastoriles en Santiago del Estero. Producir carne y madera conservando el ambiente. INTA EEA Santiago del Estero. Gobierno de la Provincia de Santiago del Estero, Santiago del Estero.

Kunst, C. R., M. Cornacchione, and S. Bravo. 1998. Características agronómicas de gramíneas del campo natural de la región chaqueña. INTA. EEA Santiago del Estero.

Kunst, C. R., R. Ledesma, and M. Navall (eds.). 2008. RBI: Rolado Selectivo de Baja Intensidad. INTA, Santiago del Estero.

Kunst, C., R. Renolfi, H. Pérez, and F. Dalla Tea. 1986. Clasificación de gramíneas de bosques y arbustales de la región chaqueña occidental por sus caracteres ecológicos y productivos. Revista Argentina de Producción Animal 6.

Ledesma, R., F. Saracco, R. Coria, F. Epstein, A. Gómez, C. Kunst, M. Ávila, and J. Pensiero. 2017. Guía de forrajeras herbáceas y leñosas del Chaco Seco: identificación y características para su manejo. Buenas prácticas para una ganadería sustentable. Kit de extensión para el Gran Chaco. Fundación Vida Silvestre Argentina. Buenos Aires, Argentina.

Molina, A. M., and Z. E. Rúgolo de Agrasar. 2006. Flora chaqueña-Argentina-(Formosa, Chaco y Santiago del Estero). Familia Gramíneas. INTA, Buenos Aires.

Morello, J. 1970. Modelo de relaciones entre pastizales y leñosas colonizadoras en el chaco argentino. IDIA 276:3152.

Morello, J., and J. Adamoli. 1968. Las grandes unidades de vegetación y ambiente del Chaco argentino. Primera parte: objetivos y metodología. INTA.

Morello, J., and J. Adamoli. 1974. Las grandes unidades de vegetación y ambiente del Chaco argentino. Segunda parte: Vegetación y ambiente de la provincia del Chaco. INTA.

Morello, J., W. Pengue, and A. Rodríguez. 2013. Un siglo de cambios de diseño del paisaje: el chaco argentino. Medio Ambiente y Urbanización 79:25-64.

Morello, J., and C. A. Saravia Toledo. 1959. El Bosque Chaqueño I. Paisaje primitivo, paisaje natural y paisaje cultural en el oriente de Salta. Revista Agronómica del Noroeste Argentino 3:5-81.

Noe, Y. E., A. C. González, H. J. Elena, and A. R. Bianchi. 2012. Distribución geográfica de las lluvias en el noroeste de Argentina (Región NOA). INTA.

van Oudenhoven, A. P. E., C. J. Veerkamp, R. Alkemade, and R. Leemans. 2015. Effects of different management regimes on soil erosion and surface runoff in semi-arid to sub-humid rangelands. Journal of Arid Environments 121:100-111. https://doi.org/10.1016/j.jaridenv.2015.05.015.

Passera, C. B., A. Dalmasso, and O. Borsetto. 1983. Método de point quadrat modificado. Taller de arbustos forrajeros para zonas áridas y semiáridas. Subcomité Asesor del Árido Subtropical Argentino, IADIZA, Mendoza.

Pensiero, J. F., J. Marcelo Zabala, L. Marinoni, and G. Richard. 2017. Recursos fitogenéticos forrajeros nativos y naturalizados (RFNyN) para suelos salinos de la región chaqueña de Argentina. In E. Taleisnik and R. S. Lavado (eds.). Ambientes salinos y alcalinos de la Argentina. Recursos y aprovechamiento productivo. Orientación Gráfica Editora, Buenos Aires, Argentina.

Puthod, G., A. Loydi, A. García, and R. A. Distel. 2020. Enhancement of palatable perennial grasses by disturbance and seed addition in degraded native grasslands of the dry pampas in Central Argentina. Arid Land Research and Management 34(4):445-459. https://doi.org/10.1080/15324982.2020.1761480. 
Ravelo, A. C., R. E. Zanavettor, and P. E. C. Boletta. 2014. Atlas de sequías de la República Argentina. CREAN / Centro de Relevamiento y Evaluación de Recursos Agrícolas y Naturales, UNC-CONICET, Córdoba, Argentina.

Ripley, B., V. Visser, P.-A. Christin, S. Archibald, T. Martin, and C. Osborne. 2015. Fire ecology of C3 and C4 grasses depends on evolutionary history and frequency of burning but not photosynthetic type. Ecology 96:2679-2691. https: //doi.org/10.1890/14-1495.1.

Scott, A. C., D. M. Bowman, W. J. Bond, S. J. Pyne, and M. E. Alexander. 2013. Fire on earth: an introduction. John Wiley and Sons, Chichester, UK.

Siffredi, G. L., F. Boggio, H. Giorgetti, J. A. Ayesa, A. Kropfl, and J. Álvarez. 2011. Guía para la Evaluación de Pastizales para las áreas ecológicas de Sierras y Mesetas Occidentales y de Monte de Patagonia Norte. Ediciones Instituto Nacional de Tecnología Agropecuaria.

Svoboda, M., M. Hayes, and D. Wood. 2012. Índice Normalizado De Precipitación. Guía de Usuario. Organización Meteorológica Mundial. Pp. 1-23. https://doi.org/978-92-63-31090-3.

Torres, R., N. I. Gasparri, P. G. Blendinger, and H. R. Grau. 2014. Land-use and land-cover effects on regional biodiversity distribution in a subtropical dry forest: a hierarchical integrative multi-taxa study. Regional Environmental Change 14:1549-1561. https://doi.org/10.1007/s10113-014-0604-1.

Tothill, J., J. Hargreaves, and R. Jones. 1978. BOTANAL. A comprehensive sampling and computing procedure for estimating pasture yield and composition. I. Field sampling. CSIRO, Australian Div. Trop. Crops and Pastures, Brisbane, Qeeensland.

Van Auken, O. W. 2000. Shrub Invasions of North American Semiarid Grasslands. Annual Review of Ecology and Systematics 31:197-215. https://doi.org/10.1146/annurev.ecolsys.31.1.197.

Van Auken, O. W. 2009. Causes and consequences of woody plant encroachment into western North American grasslands. Journal of Environmental Management 90:2931-2942. https://doi.org/10.1016/j.jenvman.2009.04.023.

Vetter, S. 2005. Rangelands at equilibrium and non-equilibrium: recent developments in the debate. Journal of Arid Environments 62:321-341. https://doi.org/10.1016/j.jaridenv.2004.11.015.

Walker, B. H. 1992. Biodiversity and ecological redundancy. Conservation biology 6:18-23. https://doi.org/10.1046/ j.1523-1739.1992.610018.x.

Zhao, Y., S. Peth, J. Krümmelbein, R. Horn, Z. Wang, M. Steffens, C. Hoffmann, and X. Peng. 2007. Spatial variability of soil properties affected by grazing intensity in Inner Mongolia grassland. Ecological Modelling 205:241-254. https: //doi.org/10.1016/j.ecolmodel.2007.02.019.

Zhou, G., X. Zhou, Y. He, J. Shao, Z. Hu, R. Liu, H. Zhou, and S. Hosseinibai. 2017. Grazing intensity significantly affects belowground carbon and nitrogen cycling in grassland ecosystems: a meta-analysis. Global Change Biology 23:1167-1179. https://doi.org/10.1111/gcb.13431. 